IZA DP No. 8335

Heterogeneity and Government Revenues:

Higher Taxes at the Top?

Nezih Guner

Martin Lopez-Daneri

Gustavo Ventura

July 2014 


\title{
Heterogeneity and Government Revenues: Higher Taxes at the Top?
}

\author{
Nezih Guner \\ ICREA-MOVE, Universitat Autonoma de Barcelona, \\ Barcelona GSE and IZA
}

Martin Lopez-Daneri

University of Southern California

Gustavo Ventura

Arizona State University

Discussion Paper No. 8335

July 2014

IZA

P.O. Box 7240

53072 Bonn

Germany

Phone: +49-228-3894-0

Fax: +49-228-3894-180

E-mail: iza@iza.org

Any opinions expressed here are those of the author(s) and not those of IZA. Research published in this series may include views on policy, but the institute itself takes no institutional policy positions. The IZA research network is committed to the IZA Guiding Principles of Research Integrity.

The Institute for the Study of Labor (IZA) in Bonn is a local and virtual international research center and a place of communication between science, politics and business. IZA is an independent nonprofit organization supported by Deutsche Post Foundation. The center is associated with the University of Bonn and offers a stimulating research environment through its international network, workshops and conferences, data service, project support, research visits and doctoral program. IZA engages in (i) original and internationally competitive research in all fields of labor economics, (ii) development of policy concepts, and (iii) dissemination of research results and concepts to the interested public.

IZA Discussion Papers often represent preliminary work and are circulated to encourage discussion. Citation of such a paper should account for its provisional character. A revised version may be available directly from the author. 


\title{
ABSTRACT \\ Heterogeneity and Government Revenues: Higher Taxes at the Top?*
}

\begin{abstract}
We evaluate the effectiveness of a more progressive tax scheme in raising government revenues. We develop a life-cycle economy with heterogeneity and endogenous labor supply. Households face a progressive income tax schedule, mimicking the Federal Income tax, and flat-rate taxes that capture payroll, state and local taxes and the corporate income tax. We parameterize this model to reproduce aggregate and cross-sectional observations for the U.S. economy, including the shares of labor income for top earners. We find that a tilt of the Federal income tax schedule towards high earners leads to small increases in revenues which are maximized at an effective marginal tax rate of about $36.9 \%$ for the richest $5 \%$ of households - in contrast to a $21.7 \%$ marginal rate in the benchmark economy. Maximized revenue from Federal income taxes is only $8.4 \%$ higher than it is in the benchmark economy, while revenues from all sources increase only by about $1.6 \%$. The room for higher revenues from more progressive taxes is even lower when average taxes are higher to start with. We conclude that these policy recommendations are misguided if the aim is to exclusively raise government revenue.
\end{abstract}

JEL Classification: E6, H2

Keywords: taxation, progressivity, labor supply

Corresponding author:

Nezih Guner

MOVE (Markets, Organizations and Votes in Economics)

Facultat d'Economia, Universitat Autònoma de Barcelona

Edifici B - Campus de Bellaterra

08193 Bellaterra

Cerdanyola del Vallès (Spain)

E-mail: nezih.guner@movebarcelona.eu

\footnotetext{
Guner acknowledges support from EU 7th Framework Collaborative Project Integrated MacroFinancial Modeling for Robust Policy Design (MACFINROBODS), Grant no. 612796, and from the Spanish Ministry of Economy and Competitiveness, Grant ECO2011-28822. We thank Juan Carlos Conesa, Mark Huggett and Tatyana Koreshkova, our discussant at the Montreal Macroeconomics Conference. We also thank seminar participants at SED, Banco Central de Chile, Banco de España, Latin-American Econometric Society, University of Cologne and Barcelona GSE Summer Workshop on Macro and Micro Perspectives on Taxation for comments. The usual disclaimer applies.
} 


\section{Introduction}

Tax reform should follow the Buffett rule: If you make more than 1 million a year, you should not pay less than $30 \%$ in taxes, and you shouldn't get special tax subsidies or deductions. On the other hand, if you make under \$250,000 a year, like 98\% of American families, your taxes shouldn't go up.

Barack Obama. State of the Union speech, January 24, 2012

Recently, calls for closing fiscal deficits have been combined with proposals to shift the tax burden and increase marginal tax rates on higher earners. The upshot is that additional tax revenue should come from those who earn higher incomes. As top earners account for a disproportionate share of tax revenues and face the highest marginal tax rates, such proposals lead to a natural tradeoff regarding tax collections. On the one hand, increases in tax collections are potentially non trivial given the revenue generated by high-income households. On the other hand, the implementation of such proposals would increase marginal tax rates precisely where they are at their highest levels and thus, where the individual responses are expected to be larger. Therefore, revenue increases might not materialize.

In this paper, we ask: how much additional revenue can be raised by making income taxes more progressive? How does the answer depend on the underlying labor supply elasticities? How does the answer depend on tax-revenue requirements (i.e. the pre-existing level of average taxes)? To address these questions, we develop an equilibrium life-cycle model with individual heterogeneity and endogenous labor supply. Individual heterogeneity is driven by initial, permanent differences in labor productivity and uninsurable productivity shocks over the life cycle. There are different forms of taxes: a non-linear income tax, a flat-rate income tax (to capture state and local taxes), a flat-rate capital income tax (to mimic the corporate income tax) and payroll taxes. ${ }^{1}$

\footnotetext{
${ }^{1}$ Our model framework is by now standard in the macroeconomic and public-finance literature, and in different versions has been used to address a host of issues. Among others, Huggett and Ventura (1998), Conesa and Krueger (1999) and Nishiyama and Smetters (2007) used it to quantify the effects of social security reform with heterogenous households. Altig, Auerbach, Kotlikoff, Smetters and Walliser (2001) used a version without uninsurable shocks to study alternative tax reforms. Ventura (1999) quantified the aggregate and distributive effects of a Hall-Rabushka flat tax. Conesa, Krueger and Kitao (2009) assessed the desirability of capital-income taxation and non-linear taxation of labor income. Heathcote, Storesletten and Violante (2010) studied the implications of rising wage inequality in the United States. See Heathcote, Storesletten and Violante (2009) for a survey of papers in the area.
} 
We discipline this model to account for aggregate and cross-sectional facts of the U.S. economy and select parameters so the model is consistent with observations on the dynamics of labor earnings, overall earnings inequality, and the relationship between individual income and taxes paid at the Federal level. In particular, in our parameterization the model economy is consistent with the shares of labor income of top earners. To capture the relationship between income and income taxes paid at the federal level, we use a parametric tax function - put forward by Benabou (2002) and used recently by Heathcote, Storesletten and Violante (2014) and others - capturing effective tax rates emerging from the Internal Revenue Service (IRS) micro data. One of these parameters governs the level of average tax rates, while the other controls the curvature, or progressivity, of the tax function. The model under this tax function accounts well for the distribution of income taxes paid in the U.S. at the Federal level, which is critical for the question we try to answer. Tax liabilities are heavily concentrated in the data - more so than the distributions of total income and labor income. In the data, the first quintile and top quintile of the distribution of income account for $0.3 \%$ and about $75 \%$ of total revenues, respectively, while the richest $1 \%$ accounts for about $23 \%$. Our model is consistent with this rather substantial degree of concentration, which is critical for the current exercise: the bottom quintile accounts for $0.4 \%$ of tax liabilities, the top quintile accounts for nearly $78 \%$, while the richest $1 \%$ accounts for about $25 \%$ of total revenues. In addition, our model implies an elasticity of taxable income for top earners of about 0.4 , a value in line with available empirical estimates.

We introduce changes in the shape of the tax function and shift the tax burden towards higher earners, via increases in the parameter that governs the curvature of the tax function. We find that income tax revenues at the Federal level are maximized at average and marginal tax rates at the top that are higher than at the benchmark economy. We find a revenuemaximizing parameter that implies an effective marginal tax rate of about $36.9 \%$ or higher for the richest $5 \%$ of households, while the corresponding value in the benchmark economy is of about $21.7 \%$. In other words, the revenue-maximizing marginal tax rates become about $15 \%$ points higher for richest top $5 \%$. However, the increase in tax revenues from income taxes at the Federal level is small. Across steady states, tax revenues from the Federal income tax increase by only about $8.4 \%$ relative to the benchmark case. Moreover, as increases in the curvature of the tax function systematically lead to reductions in savings, labor supply and output, tax collections from other sources fall across steady states. At the level of 
progressivity that maximizes the Federal income tax revenue, output declines by about $12 \%$ while the decline in savings is almost $20 \%$. As a result, overall tax collections - including corporate and state income taxes - increase only marginally by about $1.6 \%$. Therefore, the progressivity that would maximize the total tax revenue is lower: it would imply a marginal tax rate of $31.4 \%$ for the richest $5 \%$ of the households. The associated increase in total tax revenue is $2.2 \%$.

We subsequently conduct exercises to investigate the quantitative importance of different aspects of our analysis. We first investigate the importance of the labor supply elasticity. We find that when the elasticity parameter is closer to the lower end of macroeconomic estimates, the increase in income tax revenues driven by increases in the curvature of the tax function are larger than in our baseline case. The room for higher revenue is, however, still small. Choosing a degree of progressivity to maximize revenue from Federal income taxes generates about $9.9 \%$ higher revenue from Federal income taxes - in contrast to $8.4 \%$ under the benchmark elasticity value - and total revenues increase by about $2.0 \%$ - in contrast to $1.6 \%$ under the benchmark elasticity value. We then turn our attention to the magnitude of revenue requirements or the overall average tax rate, which we proxy by the 'level' parameter in the tax function. We find that there are substantial revenues available from mild increases in average rates across all households in relation to changes in progressivity. For instance, if we keep the degree of progressivity of the tax schedule intact but increase the average tax rate around mean income from $8.9 \%$ (benchmark value) to about $13 \%$, the Federal income tax revenue and total tax revenue increase by more than $31 \%$ and $19 \%$, respectively. We also show that when the average taxes are higher, there is less room for a government to raise revenue by making taxes more progressive.

Finally, we increase taxes at high incomes only - instead of generically tilting the tax function towards high earners. In particular, we search for revenue-maximizing taxes on the richest $5 \%$ of households. Our results indicate that a marginal tax rate of about $43 \%$ on the richest $5 \%$ of households maximize Federal income tax revenue. This is about 21 percentage points higher than the marginal tax rate on the top $5 \%$ of households in the benchmark economy, and about 6 percentage points higher than in the baseline scenario where we change the progressivity for the whole tax function. The resulting increase in Federal tax revenue $(8.9 \%)$ is only marginally higher than when we change the progressivity for the whole tax function (8.4\%). The rise in total tax revenue associated to a $43 \%$ marginal 
tax rate on the top $5 \%$ of households is $3.7 \%$, however, is higher than the scenario when we change the progressivity for the whole tax function (1.6\%).

To sum up, our quantitative findings indicate that there are only second-order additional revenues available from a tilt of the income-tax scheme towards high earners. These small increases in revenues are concomitant with substantial effects on output and labor supply, and require large increases in marginal tax rates for high earners. The upshot is that increases in progressivity lead to endogenous responses in the long run, that effectively result in the small effects on revenues we find. In turn, these changes in aggregates lead to reduction in tax collection from other sources, with the net effect of even smaller increases in overall revenues.

Placing our results in perspective, it is important to bear in mind the relative simplicity of our environment. As we discuss in the text, we abstract from features that would lead to even stronger forces against a tilt of the income-tax scheme towards high earners from the standpoint of tax collections. We have abstracted from human capital decisions, a bequest motive and individual entrepreneurship decisions that would be negatively affected by a steeper tax scheme. Hence, the distortions on the incentives to accumulate wealth via these channels are not taken into account in our analysis. Overall, our model provides a best chance for finding a high level of revenue-maximizing progressivity and resulting government revenues. The absence of large effects on revenues suggest that recommendations for higher progressivity are misguided if the aim is to exclusively raise government revenues.

Background Our paper is related to several strands of literature. By its focus, it is connected to research on the magnitude of relevant labor supply elasticities for use in aggregate models, and their implications for public policy. Chetty, Guren, Manoli and Weber (2011, 2013), Keane (2011) and Keane and Rogerson (2012) survey recent developments in this literature. Second, it is related to large empirical literature, reviewed by Saez, Slemrod and Giertz (2012), on the reaction of incomes to changes in marginal taxes. In this area, the recent work by Mertens (2013) is particularly relevant in light of our objectives and findings. This author finds substantial responses to changes in marginal tax rates across all income levels. $^{2}$

\footnotetext{
${ }^{2}$ His findings are consistent with macro literature that finds large effects of tax changes on GDP, e.g. Barro and Redlick (2011) and Mertens and Ravn (2013).
} 
Finally, our paper is naturally related with recent work on the Laffer curve in dynamic, equilibrium models. Trabbant and Uhlig (2011) and Fève, Matheron, and Sahuc (2014) and Holter, Krueger and Stepanchuk (2014) are examples of this work. Trabbant and Uhlig (2011) focus on the Laffer relationship driven by tax rates on different margins in the context of the one-sector growth model with a representative household. They find that while there is room for revenue gains in the U.S. economy, several European economies are close to the top of the Laffer relationship. Fève et al (2014) conduct a similar exercise in economies with imperfect insurance, where they highlight the role of government debt on the revenue-maximizing level of taxes. We differ from the first two papers in key respects, as we take into account household heterogeneity and explicitly deal with the non-linear structure of taxation in practice. These features allow us concentrate on Laffer-like relationships driven by changes in the curvature (progressivity) of the current tax scheme, and investigate the interplay between the 'level' of taxation vis-a-vis the distribution of its burden across households. Holter et al (2014), in turn, are closer to our work. These authors develop a life-cycle model with heterogeneity, non-linear taxes and labor supply decisions at the extensive margin, and study the structure of Laffer curves for OECD countries. They find that maximal tax revenues would be about $7 \%$ higher under a flat-rate tax than under the progressivity level of the U.S. They also find that at the highest progressivity levels in OECD (i.e. Denmark), substantially lower tax revenues are available.

Our paper is also related with ongoing work on the welfare-maximizing degree of tax progressivity. Conesa and Krueger (2006), Conesa et al (2009), Erosa and Koreshkova (2007), Diamond and Saez (2011), Bakis, Kaymak and Poschke (2012), Heathcote, Storesletten and Violante (2014), among others, are examples of this line of work. In particular, our paper bears close connection with Badel and Huggett (2014). These authors study a life-cycle economy where individual earnings are the outcome of risky human-capital investments. Badel and Huggett (2014) parameterize the model to account for different moment of the distribution of labor earnings, and study the welfare effects of increasing marginal tax rates on high earners. They find welfare-maximizing marginal tax rates for top earners that are higher than current ones, but leading to minuscule effects on ex-ante welfare. They also find that such higher rates lead to very small effects on government revenues. These effects on revenues become bigger - and similar to ours - when individual individual human capital (i.e. hourly wage) is exogenous. 
Our paper is organized as follows. In section 2, we present a parametric example that we use to highlight the key forces at work in our economy. In section 3, we present the life-cycle model that defines our benchmark economy, while we discuss how we assign parameter values in section 4 . We show our main results in section 5 . We provide a critical discussion of our results in section 6 . Finally, section 7 concludes.

\section{Example: The Revenue-Maximizing Degree of Pro- gressivity}

We consider the following motivating example with three central features: (i) preferences with a constant elasticity of labor supply; (ii) a log-normal distribution of wage rates; (iii) taxes represented by a parametric tax function. The example allows us to highlight the forces shaping the determination of the revenue-maximizing degree of progressivity. We then analyze the role of the labor supply elasticity, the need for revenue and the extent of heterogeneity on the revenue-maximizing degree of progressivity. We do each of this in turn.

Let preferences be represented by

$$
U(c, l)=\log (c)-\frac{\gamma}{1+\gamma} l^{1+\frac{1}{\gamma}},
$$

where $\gamma$ is the (Frisch) elasticity of labor supply. We use these preferences later on in our analysis. Individuals are heterogenous in the wage rates they face and labor is the only source of income. Wage rates are log-normally distributed. Specifically,

$$
\log (w) \sim N\left(0, \sigma^{2}\right)
$$

Finally, the tax function is given by

$$
t(\tilde{I})=1-\lambda \tilde{I}^{-\tau}
$$

where $\tilde{I}$ stands for household income relative to mean income and $t(\tilde{I})$ is the average tax rate at the relative income level $\tilde{I}$. Hence, at income $I \equiv w l$, total taxes paid amount to It $(\tilde{I})$. This parametric tax function follows Benabou (2002) and Heathcote, Storesletten and Violante (2014) and is the function that we subsequently use in our quantitative study. The parameter $\lambda$ captures the need for revenue, as it defines the level of the average tax rate. 
The parameter $\tau \geq 0$ controls the curvature of the tax function - the higher $\tau$ is, the more progressive the tax scheme is. If $\tau=0$, then the tax scheme is flat. Hence, the degree of progressivity of the tax function is controlled solely by the parameter $\tau$.

The first-order conditions for labor choice imply:

$$
\frac{w(1-\tau) \lambda \tilde{I}^{-\tau}}{w l\left(\lambda \tilde{I}^{-\tau}\right)}=l^{\frac{1}{\gamma}} .
$$

It follows that optimal labor supply is given by

$$
l^{*}(\tau)=(1-\tau)^{\frac{\gamma}{1+\gamma}} .
$$

Labor supply depends only on the curvature parameter $\tau$ and the elasticity parameter $\gamma$, independently of wage rates and $\lambda$. Labor supply is affected by $\tau$ as the distortion induced by taxation, which is given by the ratio of 1 minus the marginal tax rate to 1 minus the average rate, is constant, and equal to $(1-\tau)$. Note that the tax scheme leads to changes in labor supply even for preferences for which substitution and income effects cancel out. On the other hand, changes in wage rates and $\lambda$ generate income and substitution effects that cancel each other out exactly. This illustrates further that these preferences in conjunction with this tax function are consistent with a balanced-growth path.

Government Revenues We construct now the function that describes aggregate tax revenues, $R(\tau)$. Taxes collected from a household with wage rate $w$ are

$$
w l^{*}(\tau)\left[1-\lambda\left(\frac{w l^{*}(\tau)}{E(w) l^{*}(\tau)}\right)^{-\tau}\right],
$$

where $E(w)$ stands for mean wages. It follows that aggregate revenues are

$$
R(\tau)=l^{*}(\tau)\left[E(w)-\lambda \frac{E\left(w^{1-\tau}\right)}{[E(w)]^{-\tau}}\right] .
$$

Given the log-normal distribution of wage rates, we have

$$
\begin{gathered}
E(w)=\exp \left(\frac{1}{2} \sigma^{2}\right), \\
E\left(w^{1-\tau}\right)=\exp \left(\frac{1}{2}(1-\tau)^{2} \sigma^{2}\right),
\end{gathered}
$$


and

$$
[E(w)]^{-\tau}=\exp \left(-\frac{1}{2} \tau \sigma^{2}\right)
$$

Therefore, after some algebra, we get

$$
\begin{aligned}
R(\tau) & =l^{*}(\tau) \underbrace{\left[\exp \left(\frac{1}{2} \sigma^{2}\right)-\lambda \exp \left(\frac{1}{2}\left(1+\tau^{2}-\tau\right) \sigma^{2}\right)\right]}_{\equiv A(\tau)} \\
& =l^{*}(\tau) A(\tau) .
\end{aligned}
$$

Maximizing Revenue We start by noting that maximizing revenue entails a nontrivial choice of $\tau$, as it depends on the effects of $\tau$ on labor supply and on the function $A(\tau)$. Note that the latter function is maximized by a choice of $\tau=1 / 2$. Hence, since the effects of the curvature of the tax function on labor supply are negative, the revenue-maximizing curvature is always less than $1 / 2$.

Under an interior choice, maximizing revenues implies

$$
\frac{l^{*}(\tau)^{\prime}}{l^{*}(\tau)}=-\frac{A(\tau)^{\prime}}{A(\tau)}
$$

Hence, the revenue maximization implies a trade off between the cost of rasing $\tau$, captured by labor supply distortions, and its benefit, captures by $A(\tau)^{\prime}$ term. After some algebra, the condition boils down to

$$
-\frac{\gamma}{(1+\gamma)(1-\tau)}=\frac{\lambda \sigma^{2}(2 \tau-1)}{2\left[\exp \left((1 / 2) \sigma^{2}\left(\tau-\tau^{2}\right)\right)-\lambda\right]} .
$$

There is a unique revenue-maximizing choice of $\tau$. Note that the left-hand side of the expression above is a continuous function of $\tau$, monotonically decreasing, and becomes arbitrarily small as $\tau$ approaches 1 . The right-hand side is a continuous, strictly increasing function of $\tau$. Thus, by the intermediate-value theorem, there is a unique $\tau$ that solves equation (5). The condition that guarantees an interior solution is

$$
\frac{\lambda}{(1-\lambda)}>\frac{2 \gamma}{\sigma^{2}(1+\gamma)}
$$


That is, the choice of $\tau$ is guaranteed to be interior as long as (i) $\lambda$ is not too small; (ii) the labor supply elasticity is not too large; (iii) there is sufficient dispersion in wages. All these are quite intuitive.

Effects of Changes in Parameters We now explore the implications of changes in the parameters defining the environment on the revenue-maximizing level of $\tau$. We show the implications of the labor supply elasticity, $\gamma$, the dispersion in wages, $\sigma^{2}$, and the parameter governing the level of the average tax rate, $\lambda$. We diagrammatically illustrate in Figure 1 the effects of the changes in parameters by showing movements in the left and right-hand sides of equation 5 .

As Figure 1-a shows, an increase in the labor supply elasticity leads to a lower revenuemaximizing level of $\tau$. A higher $\gamma$ increases the cost of a higher $\tau$ as the right-hand side of equation (5) shifts down. An increase in the labor supply elasticity increases labor supply across all wage levels, but it leads to an increase in revenues - in absolute terms - that is higher at the top than at the bottom of the wage distribution. The revenue-maximizing policy is therefore to reduce the curvature parameter $\tau$ to satisfy equation (5).

Figure 1-b shows the effects of changes in the dispersion of wage rates, $\sigma^{2}$. A higher $\sigma^{2}$ increases the slope of the right-hand side of equation (5) and as a result a higher $\tau$ is associated with higher benefits in term of revenue. Indeed, an increase in wage dispersion leads to two opposing forces. First, an increase in dispersion implies more potential income at the top for a given level of labor supply, leading to an increase in $\tau$. On the other hand, a higher dispersion in wages implies more revenue from high-wage individuals. Since labor supply is negatively affected by $\tau$, this second force effectively limits the scope for higher curvature and leads to a lower level of $\tau$. The results in Figure 1-b indicate that the first force dominates, and the revenue-maximizing level of $\tau$ becomes higher than under a low value of wage dispersion.

Finally, Figure 1-c illustrates that a reduction in $\lambda$ (i.e. an increase in average tax rates) leads to a reduction in the revenue-maximizing level of $\tau$. A lower $\lambda$ reduces the slope of the left-hand side of (5) and makes lower $\tau$ values more effective for revenue maximization. This is an important prediction: if higher average tax rates are interpreted as higher revenue requirements, revenue maximization dictates a tax schedule that is less progressive. Since $\lambda$ does not affect labor supply, a reduction in $\lambda$ implies increases in revenue that are larger for 
higher wages. As $\tau$ affects negatively labor supply and in the same proportion for all wages, revenue maximization dictates an increase in individual labor supply to increase revenues further. Hence, a reduction in $\tau$ follows.

\section{Model}

We study a stationary life-cycle economy with individual heterogeneity and endogenous labor supply. Individual heterogeneity is driven by differences in individual labor productivity at the start of the life cycle, as well as by stochastic shocks as individuals age. Individuals have access to a single, risk-free asset, and face taxes of three types. They face flat-rate taxes on capital income and total income. They face labor income (payroll) taxes to finance retirement benefits. They also face a non-linear income tax schedule with increasing marginal and average tax rates. The first two tax rates are aimed at capturing the corporate income tax and income taxes at the state and local level. The non-linear tax schedule is the prime focus of our analysis, and aims to capture the salient features of the Federal Income Tax in the U.S.

Demographics Each period a continuum of agents are born. Agents live a maximum of $N$ periods and face a probability $s_{j}$ of surviving up to age $j$ conditional upon being alive at age $j-1$. Population grows at a constant rate $n$. The demographic structure is stationary, such that age $-j$ agents always constitute a fraction $\mu_{j}$ of the population at any point in time. The weights $\mu_{j}$ are normalized to sum to 1 , and are given by the recursion $\mu_{j+1}=\left(s_{j+1} /(1+n)\right) \mu_{j}$.

Preferences All agents have preferences over streams of consumption and hours worked, and maximize:

$$
E\left[\sum_{j=1}^{N} \beta^{j}\left(\prod_{i=1}^{j} s_{i}\right) u\left(c_{j}, l_{j}\right)\right] .
$$

where $c_{j}$ and $l_{j}$ denote consumption and labor supplied at age $j$. The period utility function $u$ is given by 


$$
u(c, l)=\log (c)-\varphi \frac{l^{1+\frac{1}{\gamma}}}{1+\frac{1}{\gamma}} .
$$

The parameter $\gamma$ in this formulation - central to our analysis - governs the static Frisch elasticity as well as the intertemporal labor supply elasticity. The parameter $\varphi$ controls the intensity of preferences for labor versus consumption.

Technology There is a constant returns to scale production technology that transforms capital $K$ and labor $L$ into output $Y$. This technology is represented by a Cobb-Douglas production function. The technology improves over time because of labor augmenting technological change, $X$. The technology level $X$ grows at a constant rate, $g$. Therefore,

$$
Y=F(K, L X)=A K^{\alpha}(L X)^{1-\alpha}
$$

The capital stock depreciates at the constant rate $\delta$.

Individual Constraints The market return per hour of labor supplied of an age- $j$ individual is given by $w e(\Omega, j)$, where $w$ is a wage rate common to all agents, and $e(\Omega, j)$ is a function that summarizes the combined productivity effects of age and idiosyncratic productivity shocks.

There are three types of uninsurable idiosyncratic shocks in our environment. A permanent shock $(\theta)$, a persistent shock $(z)$ and a purely temporary one $(\zeta)$. Hence, $\Omega=\{\theta, z, \zeta\}$, with $\Omega \in \Omega, \Omega \subset \Re_{+}^{3}$. Age-1 individuals receive permanent shocks according to the probability distribution $Q_{\theta}(\theta)$. We refer to these shocks as permanent as they remain constant during the working life cycle. The persistent shock $z$ follows a Markov process, with age-invariant transition function $Q_{z}$, so that $\operatorname{Prob}\left(z_{j+1}=z^{\prime} \mid z_{j}=z\right)=Q_{z}\left(z^{\prime}, z\right)$. Temporary shocks are distributed according to $Q_{\zeta}$. Hence, $\operatorname{Prob}\left(\zeta_{j+1}=\zeta^{\prime}\right)=Q_{\zeta}\left(\zeta^{\prime}\right)$. Productivity shocks are independently distributed across agents, and the law of large numbers holds. We describe the parametric structure of shocks in detail in section 4 .

All individuals are born with no assets, and face mandatory retirement at age $j=R+1$. This determines that agents are allowed to work only up to age $R$ (inclusive). An age- $j$ 
individual experiencing shocks $\Omega$ chooses consumption $c_{j}$, labor hours $l_{j}$ and next-period asset holdings $a_{j+1}$. The budget constraint for such an agent is then

$$
c_{j}+a_{j+1} \leq a_{j}(1+r)+\left(1-\tau_{p}\right) w e(\Omega, j) l_{j}+T R_{j}-T_{j}
$$

with

$$
c_{j} \geq 0, \quad a_{j} \geq 0 \quad a_{j+1}=0 \quad \text { if } j=N
$$

where $a_{j}$ are asset holdings at age $j, T_{j}$ are taxes paid, $\tau_{p}$ is the (flat) payroll social-security $\operatorname{tax}$ and $T R_{j}$ is a social security transfer. Asset holdings pay a risk-free return $r$. In addition, if an agent survives up to the terminal period $(j=N)$, then next-period asset holdings are zero. The social security benefit $T R_{j}$ is zero before the retirement age $J_{R}$, and equals a fixed benefit level for an agent after retirement.

Taxes and Government Consumption The government consumes in every period the amount $G$, which is financed through taxation, and by fully taxing individual's accidental bequests. In addition to payroll taxes, taxes paid by individuals have three components: a flat-rate income tax, a flat-rate capital income tax and a non-linear income tax scheme. Income for tax purposes $(I)$ consists of labor plus capital income. Hence, for an individual with $I \equiv w e(\Omega, j) l_{j}+r a_{j}$, taxes paid to finance government consumption at age $j$ are

$$
T_{j}=T_{f}(I)+\tau_{l} I+\tau_{k} r a_{j}
$$

where $T_{f}$ is a strictly increasing and convex function. $\tau_{l}$ and $\tau_{k}$ stand for the flat income and capital income tax rates. We later use the function $T_{f}$ to approximate effective Federal Income taxation in the United States. We will use the rates $\tau_{l}$ and $\tau_{k}$ to approximate income taxation at the state level and corporate income taxes, and $\tau_{p}$ to capture payroll (social security) taxes in the United States.

It is worth noting that as an agent's income subject to taxation includes capital (asset) income; capital income is taxed through the income tax as well as through the specific tax on capital income. It follows that an individual with income $I$ faces a marginal tax on capital income equal to $T_{f}^{\prime}(I)+\tau_{l}+\tau_{k}$. Regarding labor income, marginal tax rates are affected 
by payroll taxes as well as by income taxes. Hence, an individual with an income $I$, faces a marginal tax rate on labor income equals to $T_{f}^{\prime}(I)+\tau_{l}+\tau_{p}$.

\subsection{Decision Problem}

We now state the decision problem of an individual in our economy in the recursive language. We first transform variables to remove the effects of secular growth, and indicate transformed variables with the symbol (^). With these transformations, an agent's decision problem can be described in standard recursive fashion. We denote the individuals's state by the pair $x=(\hat{a}, \Omega), x \in \mathbf{X}$, where $\hat{a}$ are current (transformed) asset holdings and $\Omega$ are the idiosyncratic productivity shocks. The set $\mathbf{X}$ is defined as $\mathbf{X} \equiv[0, \bar{a}] \times \Omega$, where $\bar{a}$ stands for an upper bound on (normalized) asset holdings. We denote total taxes at state $(x, j)$ by $T(x, j)$. Consequently, optimal decision rules are functions for consumption $c(x, j)$, labor $l(x, j)$, and next period asset holdings $a(x, j)$ that solve the following dynamic programming problem:

$$
V(x, j)=\max _{\left(\hat{\imath}, \hat{a}^{\prime}\right)} u(\hat{c}, l)+\beta s_{j+1} E\left[V\left(\hat{a}^{\prime}, \Omega^{\prime}, j+1\right) \mid x\right]
$$

subject to

$$
\left\{\begin{array}{l}
\hat{c}+\hat{a}^{\prime}(1+g) \leq \hat{a}(1+\hat{r})+\left(1-\tau_{p}\right) \hat{w} e(\Omega, j) l+T \hat{R}_{j}-T(x, j) \\
\hat{c} \geq 0, \quad \hat{a}^{\prime} \geq 0, \quad \hat{a}^{\prime}=0 \quad \text { if } j=N \\
V(x, N+1) \equiv 0
\end{array}\right.
$$

\subsection{Equilibrium}

In our model, individuals are heterogeneous with respect to the realization of their idiosyncratic labor productivity shocks, their asset holdings, and their age. To specify the notion of equilibrium, we define a probability measure $\psi_{j}$ on subsets of the individual state space that describes heterogeneity in assets and productivity shocks within a particular cohort. Hence, for any set $B \subset \mathbf{X}, \psi_{j}(B)$ describes the mass of agents of age $j$ for with state $x \in B$. We specify this probability measure in more detail in the appendix (section 8). 
In any equilibrium, factor prices equal their marginal products. Hence, $\hat{w}=F_{2}(\hat{K}, \hat{L})$ and $\hat{r}=F_{1}(\hat{K}, \hat{L})-\delta$. Moreover, markets clear. In our context, this implies

$$
\begin{gathered}
\sum_{j} \mu_{j} \int_{X}(c(x, j)+a(x, j)(1+g)) d \psi_{j}+\hat{G}=F(\hat{K}, \hat{L})+(1-\delta) \hat{K}, \\
\sum_{j} \mu_{j} \int_{X} a(x, j) d \psi_{j}=(1+n) \hat{K},
\end{gathered}
$$

and

$$
\sum_{j} \mu_{j} \int_{X} l(x, j) e(\Omega, j) d \psi_{j}=\hat{L} .
$$

Furthermore, government budgets are balanced. This implies that government consumption equals tax collections, and that social security transfers are consistent with payroll tax collections. That is:

$$
\begin{gathered}
\hat{G}=\sum_{j} \mu_{j} \int_{X} T(x, j) d \psi_{j}+\hat{B} \\
\tau_{p} \hat{w} \hat{L}=\sum_{j=J_{R}+1}^{N} \mu_{j} T \hat{R}_{j}
\end{gathered}
$$

Note that equation (17) includes the aggregate amount of accidental bequests, $\hat{B}$. This reflects our assumption that the government fully taxes accidental bequests. In section 8 , we provide a formal notion of equilibria.

\section{Parameter Values}

We now proceed to assign parameter values to the endowment, preference, and technology parameters of our benchmark economy. To this end, we use aggregate as well as crosssectional and demographic data from multiple sources. As a first step in this process, we start by defining the length of a period in the model to be 1 year. 
Demographics We assume that individuals start life at age 25, retire at age 65 and live up to a maximum possible age of 100 . This implies that $J_{R}=40$ (age 64), and $N=75$. The population growth rate is $1.1 \%$ per year $(n=0.011)$, corresponding to the actual growth rate for the period 1990-2009. We set survival probabilities according to the U.S. Life Tables for the year $2005 .^{3}$

Endowments To parameterize labor endowments, we assume that the log-hourly wage of an agent is given by the sum of a fixed effect or permanent shock $(\theta)$, a persistent component $(z)$, a temporary component $(\zeta)$ and a common, age-dependent productivity profile, $\bar{e}_{j}$. Specifically, as in Kaplan (2012), we pose

$$
\log \left(e(\Omega, j)=\theta+\bar{e}_{j}+z_{j}+\zeta_{j}\right.
$$

with

$$
z_{j}=\rho z_{j-1}+\epsilon_{j}, \quad z_{0}=0
$$

where $\zeta_{j} \sim N\left(0, \sigma_{\zeta}^{2}\right)$ and $\epsilon_{j} \sim N\left(0, \sigma_{\epsilon}^{2}\right)$. For the permanent shock $(\theta)$, we assume that a fraction $\pi$ of the population is endowed with $\theta^{*}$ at the start of their lives, whereas the remaining $(1-\pi)$ fraction draws $\theta$ from $N\left(0, \sigma_{\theta}^{2}\right)$. The basic idea is that a small fraction of individuals within each cohort has a value of the permanent component of individual productivity that is quite higher than the values drawn from $N\left(0, \sigma_{\theta}^{2}\right)$. We refer occasionally to these individuals as superstars.

Our strategy for setting these parameters consists of two steps. First, we use available estimates and observations on individual wages (hourly earnings) to set the parameters governing the age-productivity profile and the persistence and magnitude of idiosyncratic shocks over the life. We then determine the level of inequality at the start of the life so in stationary equilibrium, our economy is in line with the level of overall earnings inequality for households. As we abstract from two-earner households in the relatively simple model of the paper, we view its implications broadly in terms of households rather than individuals. ${ }^{4}$

\footnotetext{
${ }^{3}$ National Vital Statistics Reports, Volume 58, Number 10, 2010.

${ }^{4}$ See Guner, Kaygusuz and Ventura (2012) and Bick and Fuchs-Schundeln (2013) for analyses of taxes in environments with two-earner households.
} 
We estimate the age-dependent deterministic component $\bar{e}_{j}$ by regressing mean-log wages of individuals on a polynomial of age together with time effects. We use for these purposes data from the Current Population Survey (CPS) data for 1980-2005. We consider data from males aged between 25 and 64 . We drop observations with individual wages less than half of the federal minimum wage. Moreover, as in Heathcote, Perri and Violante (2010), we impose that individuals must work at least 260 hours per year. We also correct for top-coding following Lemieux (2006).

To set values for the parameters governing heterogeneity, we proceed as follows. First, we follow Kaplan (2012) and set the autocorrrelation coefficient $(\rho)$ and the variance of the persistent innovation $\left(\sigma_{\epsilon}^{2}\right)$ to the estimates therein, $\rho=0.958$ and $\sigma_{\epsilon}^{2}=0.017 .^{5}$ We set $\pi=0.01$; i.e. we assume that $1 \%$ of each cohort are superstars. Then, we set the variance of permanent shocks for the remaining $1-\pi$ fraction and the value of the high permanent shock $\left(\theta^{*}\right)$ to reproduce two targets: i) the level of household earnings inequality - measured by the Gini coefficient - observed in U.S. data (0.55), and ii) the share of labor income at top $1 \%(14.3 \%) .{ }^{6}$ This procedure yields $\sigma_{\theta}^{2}=0.52$ and $\theta^{*}=2.9$. That is, the procedure results in superstars that are nearly eighteen times more productive than the median individual in each cohort $-18 \sim \exp (2.9)$.

Taxation Following Benabou (2002) and Heathcote, Storesletten and Violante (2014) and others, we use a convenient tax function to represent Federal Income taxes in the data. Specifically, we set the function $T_{f}$ to

$$
T_{f}(I)=I t(\tilde{I})
$$

where

$$
t(\tilde{I})=1-\lambda \tilde{I}^{-\tau}
$$

\footnotetext{
${ }^{5}$ For the results that we report in the paper, we abstract from temporary productivity (wage) shocks. We note that the magnitude of temporary wage shocks appears large in data. Kaplan (2012), for instance, estimates a variance of log-wage shocks of about 0.081. However, we choose not to present results with temporary shocks as they are very similar to the ones without them in the text. These results are available upon request.

${ }^{6}$ To calculate statistics of earnings inequality for households, we use micro data from the Internal Revenue Service (2000 Public Use Tax File). Key advantages of this data are its coverage and the absence of top coding.
} 
is an average tax function, and $\tilde{I}$ is income relative to mean income. As we indicated earlier, the parameter $\lambda$ defines the level of the tax rate whereas the parameter $\tau$ governs the curvature or progressivity of the system.

To set values for $\lambda$ and $\tau$, we use the estimates of effective tax rates for this tax function in Guner, Kaygusuz and Ventura (2014). The underlying data is tax-return, micro-data from Internal Revenue Service for the year 2000 (Statistics of Income Public Use Tax File). We use the estimates therein for all households when refunds for the Earned Income Tax Credit are included: $\lambda=0.911$ and $\tau=0.053$. These estimates imply that a household around mean income faces an average tax rate of about $8.9 \%$ and marginal tax rate of $13.7 \%$. For high income individuals, average and marginal rates are non-trivially higher. At five times the mean household income level in the IRS data (about $\$ 265,000$ in 2000 U.S. dollars), the average and marginal rates for a married household amount to $16.3 \%$ and $20.8 \%$, respectively. Figure 2 displays the resulting average and marginal tax functions.

We use the tax rate $\tau_{l}$ to approximate state and local income taxes. Guner et al (2014) find that average tax rates on state and local income taxes are essentially flat as a function of household income, ranging from about $4 \%$ at the central income quintile to about $5.3 \%$ at the top one percent of household income. From these considerations, we set this rate to $5 \%\left(\tau_{l}=0.05\right)$.

We use $\tau_{k}$ to proxy the U.S. corporate income tax. We estimate this tax rate as the one that reproduces the observed level of tax collections out of corporate income taxes after the major reforms of 1986. Such tax collections averaged about 1.74\% of GDP for 1987-2007 period. Using the technology parameters we calibrate in conjunction with our notion of output (business GDP), we obtain $\tau_{k}=0.074$.

Finally, we calculate $\tau_{p}=0.122$, as the (endogenous) value that generates an earnings replacement ratio of about $53 \% .^{7}$

Preferences and Technology We calibrate the capital share and the depreciation rate using a notion of capital that includes fixed private capital, land, inventories and consumer durables. For the period 1960-2007, the resulting capital to output ratio averages 2.93 at the annual level. The capital share equals 0.35 and the (annual) depreciation rate amounts to

\footnotetext{
${ }^{7}$ This is the value of the the median replacement ratio in the mid 2000's for 64-65 year old retirees, according to Biggs, Springstead and Glenn (2008).
} 
0.04 following the standard methodology; e.g. Cooley and Prescott (1995). This procedure also implies a rate of growth in labor efficiency of about $2.2 \%$ per year $(g=0.022)$.

We set the intertemporal elasticity of labor supply $(\gamma)$ to a value of 1 in our benchmark exercises, and later study its importance by conducting exercises for different, in particular lower, values of it. It is well known that macro estimates of the elasticity of labor supply tend to be larger than micro ones. Keane and Rogerson (2012) conclude that different mechanisms at play in aggregate settings suggest values of $\gamma$ in excess of 1 . We set the value of the parameter $\varphi$ and the discount factor $\beta$ to reproduce in stationary equilibrium a value of mean hours of $1 / 3$ and a capital to output ratio of 2.94 .

Summary Table 1 summarize our parameter choices. Four parameters $\left(\beta, \varphi, \theta^{*}\right.$ and $\left.\sigma_{\theta}^{2}\right)$ are set so as to reproduce endogenously four observations in stationary equilibrium: capital-output ratio, aggregate hours worked, earnings Gini coefficient, and the share of labor income accounted by top $1 \%$ of households.

\subsection{The Benchmark Economy}

We now discuss the quantitative properties of the benchmark economy that are of importance for the questions of this paper. We focus on the consistency of the benchmark economy with standard facts on cross-sectional inequality, as well as on a non-standard but critical fact: the distribution of taxes paid by income. We also report on the model implications for the elasticity of taxable income.

Table 2 shows that the model is in close consistency with facts on the distribution of household earnings. As the table demonstrates, the model reproduces the overall inequality in household earnings as measured by the Gini coefficient. The model is in line with the shares accounted by different quintiles, ranging from just the empirical values of $2.1 \%$ in the bottom quintile to nearly $58 \%$ in the fifth quintile. The model is also in line with the share of labor earnings accounted by top percentiles, beyond the targeted share of the top $1 \%$ earners. The share accounted for by the top 90-95\% earners in the data is of about $11.7 \%$ while the model implies $12.2 \%$. Meanwhile, the share accounted for by the top $5 \%$ earners in the data is of about $29.1 \%$ while the model implies $31.5 \%$. All this indicates that the model-implied Lorenz curve for labor earnings at the household level is in close agreement with data. 
The Distribution of Taxes Paid Table 3 shows the distribution of income-tax payments at the Federal level for different percentiles of the income distribution. As the table shows, the distribution of tax payments is quite concentrated - more so than the distributions of income and labor income. The first and second income quintiles essentially do not account for any tax liabilities, whereas the top income quintile accounts for about $75 \%$ of tax payments. The top $10 \%$ account for almost $60 \%$ of all tax payments and the richest $1 \%$ for about $23 \%$ of tax payments. This is the natural consequence of a concentrated distribution of household income and progressive income tax scheme. Table 3 shows that the model reproduces quite well the sharp rise of income tax collections across income quintiles. In particular, we note that the model generates the acute concentration of tax payments among richer households. In the data, the richest $10 \%$ of households account for about $59 \%$ of tax payments while the model implies nearly $63 \%$. Similarly, the richest $1 \%$ account for nearly $23 \%$ of tax payments while the model implies about $25 \% .^{8}$

Elasticity of Taxable Income We now proceed to report on the model-implied elasticities of taxable income, a concept that has recently garnered much attention in applied work. To this end, we first calculate the percentage change in taxable income, i.e. $w e(\Omega, j) l_{j}+r a_{j}$, and then, as it is standard in the literature, divide it by the percentage change in one minus the marginal tax rate for these income groups. We obtain an elasticity of taxable income of about 0.4 for the richest $10 \%, 5 \%$ and $1 \%$ of households, a value that lies well within the empirical estimates surveyed in Saez, Slemrod and Giertz (2012). Our estimates, however, are smaller than those recently estimated by Mertens (2013). This is not surprising. As we discuss below in the next section, our model abstracts from several features that would result in a higher value for such elasticity. ${ }^{9}$

\footnotetext{
${ }^{8}$ The facts on the distribution of tax payments reported in Table 3 are for the bottom $99.9 \%$ of the distribution of household income in the United States. Not surprisingly, the unrestricted data shows an even higher concentration of tax payments at high incomes. We present the facts in this way since as documented by Guner et al (2014) and others, a disproportionate fraction of income of the richest households is from capital-income sources. In particular, income from capital constitutes close to $65 \%$ of total household income for the richest $0.01 \%$ of households in the data. As it is well known, macroeconomic models where inequality is driven solely by earnings heterogeneity cannot account for the wealth holdings of the richest households in data.

${ }^{9}$ We compute the arc-elasticities resulting from variations in marginal tax rates associated to changes in the curvature parameter around its benchmark value. We consider changes from $\tau=0.04$ to $\tau=0.06$. Considering other variations in curvature around the benchmark value do not change the resulting elasticities in a significant way.
} 


\section{Findings}

We now report on the consequences of shifting the tax burden towards top earners. Specifically, we fix the 'level' parameter of the tax function $(\lambda)$ at its benchmark value, and vary the parameter governing its curvature or progressivity $(\tau)$. For each case, we compute a steady state in our economy and report on a host of variables.

Table 4 shows the consequences of selected values for the curvature parameter $\tau$, ranging from 0 (a proportional tax) to 0.16 - above and below the benchmark value case, $\tau=0.053$. Two prominent findings emerge from the table. First, it takes a non-trivial increase in the the curvature parameter, from 0.053 to 0.13 , in order to maximize revenues from the Federal income tax. The resulting aggregate effects associated to increasing curvature are substantial. Increasing the curvature parameter from its benchmark value to 0.13 reduces capital, output and labor supply (in efficiency units) by about 19\%, $11.6 \%$ and $7.2 \%$, respectively. These values are quantitatively important, and result from a significant rise in marginal rates relative to average rates, as we discuss below. This rise leads to standard reductions in the incentives on the margin to supply labor and save, which in equilibrium translate into the substantial effects on aggregates just mentioned. Figure 3-a illustrates the resulting effects on labor supply, capital and output from changing the curvature parameter $\tau$ for a wide range of values.

Second, the increase in revenues associated to the changes in progressivity are relatively small in comparison to the large implied reductions in output. Maximizing revenues implies an increase in income taxes at the federal level of about $8.4 \%$, or about $0.9 \%$ of output in the benchmark economy. Increasing progressivity also leads to a reduction in tax collections at the local and state level and from corporate income taxes. This occurs as tax collections from these sources are roughly proportional to the size of aggregate output and capital. As a result, tax collections from all sources are maximized at a lower level of progressivity (at $\tau=0.10$ ), and increase only by about $1.6 \%$ at the level of progressivity consistent with revenue maximization from the Federal income tax.

Figure 3-b illustrates the effects on from changing the curvature parameter $\tau$ on government revenues - Federal and Total - in relation to the benchmark economy. The figure clearly depicts a Laffer-like curve associated to changes in progressivity. As the figure shows, both relationships are relative flat around maximal revenues, as non-trivial changes in curvature 
are associated with rather small changes in revenues.

Magnitude of Changes in Tax Rates How large are the required changes in average and marginal rates resulting from the revenue-maximizing shifts in progressivity? We assess the implications of these changes using the tax function in the benchmark economy and compare it with the resulting tax function that maximizes revenue from Federal income taxes as well as total taxes (these functions have the level parameter $\lambda$ as in the benchmark economy, but higher curvature parameter $\tau$ ). We illustrate these changes by focusing on the average and marginal tax rates for households at the top 10\%, 5\% and 1\%, respectively.

As the top panel of Table 5 shows, at the benchmark economy, average rates are about 15.7, 17.4 and 20.7 percent for richest $10 \%, 5 \%$ and $1 \%$ of households, respectively. The corresponding marginal rates amount to 20.2, 21.7, and 24.9 percent. At maximal revenue for Federal income taxes (when $\tau=0.13$ ), average rates at the top levels are 24.1, 27.5 and 34.4 percent, and marginal rates amount to $33.9,36.9$ and 42.9 percent, respectively. In other words, for the richest 5 percent of households in our economy, revenue maximization dictates an increase in average rates of nearly ten percentage points, and an increase in marginal rates of about fifteen percentage points. Hence, revenue-maximizing tax rates are non-trivially larger than those at the benchmark economy. From these perspective, the concomitant large effects on aggregates are not surprising. As we have already mentioned above, these large effects on aggregates imply that the value of $\tau$ that maximizes total revenue - rather than Federal income revenues only - is lower as shown in the last column of Table 5 .

The Distribution of Tax Payments Not surprisingly, the shifts in progressivity lead to non-trivial shifts on the contribution to income tax payments by households at different income levels, or tax burden for short. The bottom panel of Table 5 shows changes in the tax burden associated to the move from the benchmark level of progressivity to values around the maximal revenue levels $(\tau=0.13$ and $\tau=0.1)$. The results show a significant shift in terms of the distribution of the tax burden, and mirror the consequences on aggregates and tax rates above. From the benchmark case to revenue-maximizing levels, the share of taxes paid by the richest $20 \%$ increase by about nine percentage points, with equivalent increases at higher income levels. The shares of taxes paid at the bottom of the income distribution 
change much less, with the poorest $20 \%$ changing from nearly no taxes paid to a negative contribution as their average tax rates turn negative.

Who Reacts? As we discussed above, higher values of $\tau$ result in significant declines in aggregate savings, labor supply and as a result, in aggregate output. We now concentrate on the decline in labor supply and savings in more detail. The upper panel of Table 6 shows how labor supply (in efficiency units) changes for households at different percentiles of the income distribution. To fix ideas, we focus on two levels of curvature: $\tau=0.13$ that maximizes the Federal income tax revenue, and $\tau=0.1$ that maximizes the aggregate tax revenue. A central result in Table 6 is that the decline in aggregate labor supply, as progressivity increases, is rather uniform across income levels. When $\tau=0.13$, labor supply declines by about 7-8\%, while the decline amounts to about $4-5 \%$ when $\tau=0.1$. Very productive (rich) households react slightly more; the decline in the labor supply of the richest households is of about $8-9 \%$ when $\tau=0.13$.

At the conceptual level, a decline in labor supply that is relatively uniform across income levels is connected to (i) the functional form for individual preferences we adopted and (ii), the specific tax function that we use to capture the relationship between tax rates and household income. This is clear from the simple, static case discussed in section 2 , where the curvature factor $\tau$ affects all agents in a symmetric way. From this standpoint, the results in Table 6 are not surprising. At the empirical level, the similar reaction in labor supply across income levels is in broad consistency with the recent empirical findings of Mertens (2014; Table IV and Figure 6), who uncovers systematic effects on wage income associated to marginal-tax rate changes across all income levels.

We now concentrate on the effect of higher progressivity on savings. The lower panel of Table 6 shows how the wealth distribution implied by the model changes with the curvature parameter. The results in the table show that increasing tax progressivity leads to significant reductions in wealth concentration. In the benchmark economy, the share of wealth in the top quintile is about $76 \%$, with an overall Gini coefficient of about $0.73 .{ }^{10}$ Under $\tau=0.10$

\footnotetext{
${ }^{10}$ The model generates substantial wealth inequality, but not as much as in U.S. data. The wealth-Gini coefficient in the model is 0.73 versus a data value of about 0.80 . In particular, the model is not successful in generating the extreme wealth holdings at the top observed in the data; see for instance Budria Rodriguez, Diaz-Jimenez, Quadrini, and Rios-Rull (2002). This is not surprising; it is well known in the literature that a model that is parameterized in line with earnings-distribution observations will have a hard time in generating the observed wealth distribution in the data.
} 
the share of the top quintile drops to about $69 \%$, and under $\tau=0.13$ it drops even further to about $64 \%$. Overall, these findings indicate asymmetric responses in terms of household savings, which lead to a reduction in the concentration of wealth as progressivity increases. This is expected: increasing progressivity leads to larger differences in the after-tax rate of return on assets between richer and poorer households. These disproportionate change in incentives to accumulate assets upon changes in progressivity are reflected in ensuing wealth distributions.

Summary and Discussion The message from these findings is clear. There is not much available revenue from revenue-maximizing shifts in the burden of taxation towards high earners - despite the substantial changes in tax rates across income levels - and these changes have non-trivial implications for economic aggregates. Figures 3 a-b summarize these findings. As we argue below, this conclusion does not depend critically on the magnitude of the labor-supply elasticity. Moreover, in line with the analytical results in 2 , the limits for revenue maximization via changes in progressivity become more demanding as revenue requirements increase.

At the big-picture level, it is important to reflect on the absence of features in our model that would make our conclusions even stronger. First, we have abstracted from human capital decisions that would be negatively affected by increasing progressivity. The work by Erosa and Koreshkova (2007), Guvenen, Kuruscu and Ozcan (2014), Huggett and Badel (2014) and others naturally implies that individual skills are not invariant to changes in tax progressivity and thus, larger effects on output and effective labor supply - relative to a case with exogenous skills - are to be expected. From this standpoint, increasing tax progressivity would lead to an even lower increase in government revenues. Second, we have not model individual entrepreneurship decisions and their interplay with the tax system. Meh (2005), for instance, finds effects on steady-state output from a shift from a progressive income tax to a proportional tax that are larger when entrepreneurs are explicitly considered. Finally, we have not modeled a bequest motive, or consider a dynastic framework more broadly. In these circumstances, it is natural to conjecture that the sensitivity of asset accumulation decisions to changes in progressivity would be larger than in a life-cycle economy. Hence, smaller effects on revenues would follow.

To sum up, our model environment provides a reasonable upper bound on the potential 
effects of increasing progressivity on tax revenues. Even smaller effects are likely to emerge in an environment with the features mentioned above.

\section{Findings in Perspective}

We now attempt to put our findings in perspective. To this end, we provide calculations to highlight the importance of aspects of our environment that might be critical for our results. We conduct three distinct exercises. First, we investigate the role of the labor supply elasticity for aggregates and government revenues when progressivity changes. Second, we evaluate the quantitative importance of the 'level' of revenues for the revenue-maximizing level of progressivity. Finally, we conduct exercises where instead of tilting the entire tax function, we change only the marginal tax rate at high income levels.

\subsection{What is the Importance of the Labor Supply Elasticity?}

To what extent our findings depend on the magnitude of $\gamma$, the labor elasticity parameter? The reader should recall that we have assumed a benchmark value of 1 for this parameter. As it is well known, there is a debate about the appropriate magnitude of the intertemporal elasticity and its value in macroeconomic models. In a recent survey, Rogerson and Keane (2012) conclude that a several economic mechanisms can rationalize aggregate observations for a value of $\gamma$ between 1 and 2 in macroeconomic models. From these perspective, our benchmark value is at the bottom of the range. On the other hand, Chetty et al (2011 and 2013) argue for an elasticity of around 0.75 for macroeconomic models. As a result, we consider two cases for the elasticity parameter around the benchmark value: $\gamma=0.75$ and $\gamma=1.25$. For each of these cases, we recalibrate the model to reproduce the same targets discussed in section 4 .

Our results are summarized in Table 7 alongside the results for the benchmark case. Three central findings emerge from the table. First, not surprisingly, output and labor supply respond more to changes in the curvature of the tax function when the elasticity value is higher. For a given curvature value, the consequences of the implied distortion on labor supply decisions become bigger under higher values of the elasticity parameter $\gamma$ and thus, the equilibrium responses on labor supply and output are larger. Second, in line with results from the simple example discussed in section 2 , the level of curvature that maximizes 
revenue is negatively related to the value of the elasticity parameter. Quantitatively, the value of the curvature parameter $\tau$ that maximizes revenue is not critically affected by the elasticity parameter: the level of $\tau$ that maximizes revenue is 0.13 under $\gamma=1.25$ and it is around 0.14 under $\gamma=0.75$. Figure 4-a displays revenues from the Federal income tax as a function of the curvature parameter for the three values of the labor-supply elasticity.

Finally, from Table 7 and Figure 4-a is clear that our conclusions in section 5 still hold: quantitatively, there is not much revenue available from a tilt of the tax schedule towards high earners. Table 7 shows that under the low value of $\gamma(0.75)$, maximal revenues from Federal income taxes are about $9.9 \%$ higher than in the benchmark case, while they were about $8.4 \%$ higher than in the benchmark case under $\gamma=1$. Overall tax collections increase by about $2.5 \%$ whereas they do so by about $1.6 \%$ in under the baseline value of $\gamma$.

\subsection{What is the Importance of Revenue Requirements?}

In section 2, we showed that a higher level of revenue requirement or the average tax rate, as defined by the level parameter $\lambda$ in the tax function, implies lower values of the revenuemaximizing curvature parameter $\tau$. That is, lower distortions in labor supply choices. Quantitatively, how important is this effect in our dynamic model? More broadly, what is the role of revenue requirements on aggregates and government revenues?

Table 8 shows the consequences of two lower values of $\lambda, \lambda=0.87$ and $\lambda=0.85$, alongside the benchmark value $\lambda=0.911$, for different values of the curvature parameter $\tau$. Values of all variables are normalized to 100 at the benchmark economy. In understanding these results, the reader should note that by changing the value of $\lambda$, we leave unaltered the value of the ratio of one minus the marginal tax rate to one minus the average tax rate - the proxy for distortions - as this ratio is independent from $\lambda$.

Table 8 shows that higher revenue requirements (lower $\lambda$ ), for a given value of curvature, lead to mildly lower values of labor supply and output. For instance, at the extreme value of $\tau=0.16$, output under $\lambda=0.85$ is about $5.8 \%$ lower than under the benchmark value of $\gamma$. Moreover, and in line with the example in section 5, maximal revenues for Federal income taxes indeed take place at lower values of progressivity. In the benchmark case, income tax revenues are maximal at $\tau=0.13$. Under the high-revenue requirement value of $\lambda=0.85$, revenue maximization takes place at values much closer to the benchmark value of curvature 
at $\tau=0.09$. Figure 4 -b displays revenues from the Federal income tax as a function of the curvature parameter for the three values of the level parameter $\lambda$.

Table 8 shows that there are rather substantial gains in revenues associated to changes in the level of the average tax rate for a given level of progressivity. A change in $\lambda$ from 0.911 to 0.87 , which translates into an increase in the average rate at mean income from $8.9 \%$ to $13 \%$, raises revenues by more than $30 \%$. This increase in revenue is rather substantial in relation to the increases in revenue available under changes in progressivity, and implies only minimal reductions in aggregates and tax collections from other sources. Of course, the welfare implications of such distinct changes in the structure of taxation are different and involve usual equity and efficiency trade-offs.

\subsection{Higher Taxes at the Top - Only}

In our main exercises, we increase progressivity by increasing the curvature parameter, $\tau$. This tilt of the tax function towards high earners actually reduces tax rates for income levels at the bottom. We ask now whether it is possible to increase revenues substantially from Federal income taxes by only taxing more heavily top incomes. For these purposes, we modify the tax function via increases in marginal tax rates above high income levels.

Concretely, let the new tax function with higher marginal rates at top incomes be given by $T_{N E W}(\tilde{I})$. Let $\tilde{I}_{H}$ be the level of relative income after which higher marginal rates are imposed, and $\tau_{H}$ be the higher marginal tax rate above $\tilde{I}_{H}$. Hence,

$$
T_{N E W}(\tilde{I})=T(\tilde{I})
$$

if $\tilde{I} \leq \tilde{I}_{H}$, and

$$
T_{N E W}(\tilde{I})=T\left(\tilde{I}_{H}\right)+\tau_{H}\left(\tilde{I}-\tilde{I}_{H}\right)
$$

if $\tilde{I}>\tilde{I}_{H}$.

In this case, the marginal tax rate at top incomes is constant and equal to $\tau_{H}$. We concentrate on higher tax rates for the top $5 \%$. Since in the benchmark case, as discussed in the previous section, the marginal tax rate defining the richest $5 \%$ amounts to about $21.7 \%$, we consider levels of $\tau_{H}$ above this value. It turns out that the marginal tax rate $\left(\tau_{H}\right)$ that maximizes revenues from the Federal income is about 43\%. Revenues from Federal income 
taxes are effectively $8.9 \%$ higher than in the benchmark economy, while in our main exercises revenues increase by $8.4 \%$.

We find that, as did above and not surprisingly, higher marginal tax rates reduce labor supply, capital and output in a significant way. Increasing the marginal tax rate for top incomes to $43 \%$ reduces labor supply, capital and output by $4.2 \%, 9.1$ and $5.9 \%$, respectively. Revenue maximization for all taxes takes place at a value of $\tau_{H}$ around $40 \%$, with revenue increases up to $3.9 \%$. We obtain similar findings when higher marginal tax rates are applied to the richest $1 \%$ - albeit with smaller revenue increases.

We conclude that the results from these exercises reinforce our main conclusions that there is not much revenue available from shifting the tax burden towards top earners.

\section{Concluding Remarks}

The effectiveness of a more progressive tax scheme in raising tax revenues is rather limited. This occurs despite the substantial increases in tax rates for higher incomes that is needed to attain maximal revenues. Large changes in output, capital and labor supply take place across steady states in response to increases in progressivity that effectively result in secondorder increases in government revenues. This conclusion is robust to values of the parameter governing the labor supply elasticity on the low side of values for macro models and to whether tax rates are increased only at the top.

We find, nonetheless, that there are substantial revenues available from 'level' shifts of the tax function. These shifts correspond to changes in average and marginal tax rates for all in about the same magnitude, that distort household behavior less. In consequence, the resulting changes in macroeconomic aggregates are much smaller and the effects on tax revenues substantial. We also find that when the level of taxes are high, there is even lesser room for a government to raise revenue by making them more progressive. Altogether, our findings suggest that increasing progressivity is misguided if the aim is to exclusively raise government revenue. 


\section{Appendix: Equilibrium Definition}

We define formally a stationary recursive competitive equilibrium. For aggregation purposes, a probability measure $\psi_{j}$, all $j=1, N$, defined on subsets of the individual state space will describe the heterogeneity in assets and productivity shocks within a particular cohort. Let $\left(\mathbf{X}, B(\mathbf{X}), \psi_{j}\right)$ be a probability space where $B(\mathbf{X})$ is the Borel $\sigma$-algebra on $\mathbf{X}$. The probability measure $\psi_{j}$ must be consistent with individual decision rules that determine the asset position of individual agents at a given age, given the asset history and the history of labor productivity shocks. Therefore, it is generated by the law of motion of the productivity shocks $\Omega$ and the asset decision rule $a(x, j)$. The distribution of individual states across age 1 agents is determined by the exogenous initial distribution of labor productivity shocks $Q_{\theta}$ and persistent and temporary innovations since agents are born with zero assets. For agents $j>1$ periods old, the probability measure is given by the recursion:

$$
\psi_{j+1}(B)=\int_{X} P(x, j, B) d \psi_{j}
$$

where

$$
P(x, j, B)=\left\{\begin{array}{ll}
Q_{z}\left(z^{\prime}, z\right) Q_{\zeta^{\prime}} & \text { if }\left(a(x, j), z^{\prime}, \zeta^{\prime}\right) \in B \\
0 & \text { otherwise }
\end{array} .\right.
$$

It is possible now to state the definition of steady state equilibrium:

Definition: A steady state equilibrium is a collection of decision rules $c(x, j), a(x, j)$, $l(x, j)$, factor prices $\hat{w}$ and $\hat{r}$, taxes paid $T(x, j)$, per-capita accidental bequests $\hat{B}$, social security transfers $\widehat{T R}_{j}$, aggregate capital $\hat{K}$, aggregate labor $\hat{L}$, government consumption $\hat{G}$, a payroll tax $\tau_{p}$, and a tax regime $\left\{T_{f}, \tau_{l}, \tau_{k}\right\}$ and distributions $\left(\psi_{1}, \psi_{2}, \ldots, \psi_{N}\right)$ such that

1. $c(x, j), a(x, j)$ and $l(x, j)$ are optimal decision rules.

2. Factor Prices are determined competitively: $\hat{w}=F_{2}(\hat{K}, \hat{L})$ and $\hat{r}=F_{1}(\hat{K}, \hat{L})-\delta$

3. Markets Clear:
(a) $\sum_{j} \mu_{j} \int_{X}(c(x, j)+a(x, j)(1+g)) d \psi_{j}+\hat{G}=F(\hat{K}, \hat{L})+(1-\delta) \hat{K}$
(b) $\sum_{j} \mu_{j} \int_{X} a(x, j) d \psi_{j}=(1+n) \hat{K}$ 
(c) $\sum_{j} \mu_{j} \int_{X} l(x, j) e(z, j) d \psi_{j}=\hat{L}$

4. Distributions are Consistent with Individual Behavior:

$$
\psi_{j+1}(B)=\int_{X} P(x, j, B) d \psi_{j}
$$

for $j=1, \ldots, N-1$ and for all $B \in B(X)$.

5. Government Budget Constraint is satisfied:

$$
\hat{G}=\sum_{j} \mu_{j} \int_{X} T(x, j) d \psi_{j}+\hat{B}
$$

where

$$
\widehat{B}=\left[\sum_{j} \mu_{j}\left(1-s_{j+1}\right) \int_{X}(a(x, j)(1+\widehat{r})) d \psi_{j}\right] /(1+n)
$$

6. Social Security Benefits equal Taxes:

$$
\tau_{p} \hat{w} \hat{L}=\sum_{j=J_{R}+1}^{N} \mu_{j} \widehat{T R}_{j}
$$




\section{References}

[1] Altig, D., Auerbach, A., Kotlikoff, L., Smetters, K., and J. Walliser, "Simulating Fundamental Tax Reform in the United States." American Economic Review, 2001, 91(3), pp. 574-595.

[2] Badel, A. and M. Huggett, "Taxing Top Earners: A Human Capital Perspective." Mimeo, 2014.

[3] Barro, R. J. and C. J. Redlick, "The Macroeconomic Effects of Government Purchases and Taxes." Quarterly Journal of Economics, 2011, 126(1), pp. 51-102.

[4] Bakis, O., Kaymak, B. and M. Poshke, "On the Optimality of Progressive Income Redistribution." 2012, CIREQ Working Paper 10-2012.

[5] Benabou, Rolland, "Tax and Education Policy in a Heterogeneous-Agent Economy: What Levels of Redistribution Maximize Growth and Efficiency?" Econometrica, 2002, 70(2), pp. 481-517.

[6] Bick, A. and N. Fuchs-Schundeln. "Taxation and Labor Supply of Married Women across Countries: A Macroeconomic Analysis." Mimeo, 2013.

[7] Biggs, A. and G. Springstead, "Alternate Measures of Replacement Rates for Social Security Benefits and Retirement Income." Social Security Bulletin, 2008, 68(2).

[8] Budria Rodriguez, S., Diaz-Gimenez, J., Quadrini, Vincenzo, and Jose-Victor Rios-Rull, "Updated Facts on the U.S. Distributions of Earnings, Income and Wealth," Federal Reserve Bank of Minneapolis Quarterly Review, 2002, Summer, 2-35.

[9] Chetty, R., Guren, A., Manoli D. and A. Weber, "Are Micro and Macro Labor Supply Elasticities Consistent? A Review of Evidence on the Intensive and Extensive Margins," American Economic Review Papers and Proceedings. 2011, 101(2), pp. 471-475.

[10] Chetty, R., Guren, A., Manoli D. and A. Weber, "Does Indivisible Labor Explain the Differences between Micro and Macro Elasticities: A Meta-Analysis of Extensive Margin Elasticities." 2012 NBER Macroeconomics Annual, vol. 27. 2013, pp. 1-56. 
[11] Conesa, J. C. and D. Krueger, "On the Optimal Progressivity of the Income Tax Code," Journal of Monetary Economics. 2006, 53(7), pp. 1425-1450.

[12] Conesa, J. C., Kitao, S. and D. Krueger. "Taxing Capital? Not a Bad Idea after All!," American Economic Review. 2009, 99(1), pp. 25-48.

[13] Cooley, T. F. and E. Prescott, "Economic Growth and Business Cycles," in T. F. Cooley, ed., Frontiers of Business Cycle Research, Princeton University Press, 1995, pp. 1-38.

[14] Diamond, P. and E. Saez. "The Case for a Progressive Tax: From Basic Research to Policy Recommendations." Journal of Economic Perspectives 2011, 25(4), pp. 165-90.

[15] Erosa, A. and T. Koreshkova. "Progressive Taxation in a Dynastic Model of Human Capital," Journal of Monetary Economics 2007, 54(3), pp. 667-685.

[16] Fève, P., Matheron, J. and J. Sahuc. "The Laffer Curve in an Incomplete-Market Economy." Mimeo, 2014.

[17] Guner, N., Kaygusuz, R. and G. Ventura. "Taxation and Household Labor Supply." The Review of Economic Studies 2012, 79(3), pp. 1113-1149.

[18] Guner, N., Kaygusuz, R. and G. Ventura. "Income taxation of U.S. households: Facts and parametric estimates", Review of Economic Dynamics. 2014, Forthcoming.

[19] Guvenen, F., Kuruscu, B and S. Ozkan. "Taxation of Human Capital and Wage Inequality: A Cross-Country Analysis". Review of Economic Studies, 2014, 81, pp. 818-850.

[20] Heathcote, J., F. Perri, and G. L. Violante, "Unequal We Stand: An Empirical Analysis of Economic Inequality in the United States, 1967-2006." Review of Economic Dynamics, 2010, 13(1), 15-51.

[21] Heathcote, J., K. Storesletten, and G. L. Violante, "The Cross-Sectional Implications of Rising Wage Inequality in the United States," Journal of Political Economy, 2010, 118(4), 681-722.

[22] Heathcote, J., Storesletten, J. and G. L. Violante. "Quantitative Macroeconomics with Heterogeneous Households," Annual Review of Economics, 2009, 1, pp. 319-354. 
[23] Heathcote, J., Storesletten, J. and G. L. Violante. "Optimal Tax Progressivity: An Analytical Framework." Mimeo, 2014.

[24] Holter, H. A., Krueger, D., and S. Stepanchuk. "How Does Tax-Progressivity Affect OECD Laffer Curves?" Mimeo, 2014.

[25] Huggett, M. and G. Ventura, "On the Distributional Effects of Social Security Reform." Review of Economic Dynamics, 1999, 2(3), pp. 498-531.

[26] Kaplan, G. "Inequality and the Lifecycle." Quantitative Economics, 2012, 3(3), pp. 471-525.

[27] Keane, Michael P., "Labor Supply and Taxes: A Survey." Journal of Economic Literature, 2011, 49(4), pp. 961-1075.

[28] Keane, M. and R. Rogerson, "Reconciling Micro and Macro Labor Supply Elasticities: A Structural Perspective." Mimeo, 2012.

[29] Lemieux, T. "Increasing Residual Wage Inequality: Composition Effects, Noisy Data, or Rising Demand for Skill?" American Economic Review, 2006, 96(3), pp. 461-498.

[30] Meh, C. "Entrepreneurship, Wealth Inequality, and Taxation", Review of Economic Dynamics 2005, 8(3), pp. 688-719.

[31] Mertens, K. "Marginal Tax Rates and Income: New Time Series Evidence." Mimeo. 2013.

[32] Mertens, K. and Morten R.. "The Dynamic Effects of Personal and Corporate Income Tax Changes in the United States." American Economic Review, 103(4), pp. 1212-47.

[33] Nishiyama, S. and K. Smetters, "Does Social Security Privatization Produce Efficiency Gains?" The Quarterly Journal of Economics, 2007, 122 (4), pp. 1677-1719.

[34] Saez, E., Slemrod J. and S.H. Giertz. "The Elasticity of Taxable Income with Respect to Marginal Tax Rates: A Critical Review." Journal of Economics Literature 50(1), pp. $3-50$. 
[35] Trabandt, M. and H. Uhlig, "The Laffer Curve Revisited." Journal of Monetary Economics, 2011, 58 (4), pp. 305-327.

[36] Ventura, G., "Flat Tax Reform: A Quantitative Exploration." Journal of Economic Dynamics \& Control, 1999, 23(9-10), pp. 1425-1458. 
Table 1: Parameter Values

\begin{tabular}{l|c|l}
\hline \hline & Value & Comments \\
\cline { 2 - 2 } Parameter & 1.1 & U.S. Data \\
Population Growth Rate $(n)$ & 2.2 & U.S. Data \\
Labor Efficiency Growth Rate $(g)$ & 0.983 & Calibrated - matches $K / Y$ \\
Discount Factor $(\beta)$ & 1 & Literature \\
Intertemporal Elasticity $(\gamma)$ & 8.7 & Calibrated - matches hours \\
Disutility of Market Work $(\varphi)$ & 0.35 & Calibrated \\
Capital Share $(\alpha)$ & 0.04 & Calibrated \\
Depreciation Rate $\left(\delta_{k}\right)$ & & \\
& 0.958 & Kaplan $(2012)$ \\
Autocorrelation Permanent Shocks $(\rho)$ & 0.520 & Calibrated - matches Earnings Gini \\
Variance Permanent Shocks $\left(\sigma_{\theta}^{2}\right)$ & 0.017 & Kaplan $(2012)$ \\
Variance Persistent Shocks $\left(\sigma_{\epsilon}^{2}\right)$ & 0.01 & \\
Share of Superstars $(\pi)$ & 2.9 & Calibrated - matches labor income \\
Value of Superstars Productivity $\left(\theta^{*}\right)$ & & share of top 1\% \\
& & \\
Payroll Tax Rate $\left(\tau_{p}\right)$ & 0.122 & Calibrated \\
Capital Income Tax Rate $\left(\tau_{k}\right)$ & 0.074 & Calibrated \\
Income Tax Rate $\left(\tau_{l}\right)$ & 0.05 & Calibrated \\
Tax Function Level $(\lambda)$ & 0.911 & Guner et al $(2013)$ \\
Tax Function Curvature $(\tau)$ & 0.053 & Guner et al $(2013)$ \\
\hline \hline
\end{tabular}

Note: Entries show parameter values together with a brief explanation on how they are selected. See text for details. 
Table 2: Shares of Labor Income (\%) - Model and Data

\begin{tabular}{|l|c|c|}
\hline Percentiles & Data & Model \\
\hline Quantile & & \\
1st (bottom 20\%) & 2.1 & 3.2 \\
2nd (20-40\%) & 6.7 & 6.8 \\
3rd (40-60\%) & 12.3 & 11.2 \\
4th (60-80\%) & 21.3 & 19.1 \\
5th (80-100\%) & 57.6 & 59.8 \\
Top & & \\
90-95\% & 11.7 & 12.2 \\
$5 \%$ & 29.1 & 31.5 \\
$1 \%$ & 14.3 & 14.1 \\
\hline Gini Coefficient & 0.55 & 0.55 \\
\hline
\end{tabular}

Note: Entries shows the distribution of labor income in the data and the the implied distribution from our model. The labor-income data is from the Internal Revenue Service for the year 2000 (Statistics of Income Public Use Tax File). See text for details. 
Table 3: Shares of Tax Payments - Model and Data

\begin{tabular}{|l|c|c|}
\hline Percentiles of & Data & Model \\
\hline Quantile & & \\
\hline 1st (bottom 20\%) & 0.3 & 0.4 \\
2nd (20-40\%) & 2.2 & 2.5 \\
3rd (40-60\%) & 6.9 & 5.7 \\
4th (60-80\%) & 15.9 & 13.7 \\
5th (80-100\%) & 74.6 & 77.8 \\
Top & 59.0 & 62.6 \\
$10 \%$ & 22.7 & 25.2 \\
\hline $1 \%$ & & \\
\hline Tax Revenue (\% GDP) & 10.1 & 11.2 \\
\hline
\end{tabular}

Note: Entries shows the distribution of taxes paid (Federal Income taxes) in the data and the the implied distribution from our model. The tax data is from the Internal Revenue Service for the year 2000 (Statistics of Income Public Use Tax File). The last row displays Federal Income tax collections as a percentage of output (GDP). See text for details.

Table 4: Changes in Progressivity

\begin{tabular}{|l|c|c|c|c|c|c|}
\hline & $\tau=0$ & $\tau=0.04$ & $\tau=0.08$ & $\tau=0.10$ & $\tau=0.13$ & $\tau=0.16$ \\
Output & 108.7 & 102.1 & 95.8 & 92.8 & 88.4 & 84.2 \\
Hours & 104.2 & 101.1 & 97.7 & 95.9 & 93.0 & 90.1 \\
Labor Supply & 104.6 & 101.2 & 97.5 & 95.6 & 92.8 & 89.8 \\
Capital & 116.6 & 103.7 & 92.8 & 87.8 & 81.0 & 74.6 \\
& & & & & & \\
Revenues & & & & & \\
Federal Income Tax & 82.1 & 96.7 & 104.9 & 107.0 & 108.4 & 107.7 \\
Corporate Income Tax & 104.7 & 101.2 & 97.3 & 95.3 & 92.1 & 88.9 \\
State and Local Taxes & 107.7 & 101.9 & 96.2 & 93.4 & 89.3 & 85.3 \\
All Taxes & 91.3 & 98.5 & 101.8 & 102.2 & 101.6 & 99.8 \\
\hline
\end{tabular}

Note: Entries shows the effects across steady states of changes in the curvature (progressivity) of the tax function on selected variables. Values of all variables are normalized to 100 in the benchmark economy. The 'All Taxes' row includes Federal income and corporate taxes plus state and local taxes. See text for details. 
Table 5: Shares of Tax Payments and Tax Rates- Benchmark and Higher Progressivity

\begin{tabular}{|l|c|c|c|}
\hline \hline Percentiles of Income & $\begin{array}{c}\tau=0.053 \\
\text { (benchmark) }\end{array}$ & $\tau=0.13$ & $\tau=0.10$ \\
top 10\% & \multicolumn{3}{|c|}{ Average Tax Rate } \\
top 5\% & 15.7 & 24.1 & 21.1 \\
top 1\% & 17.4 & 27.5 & 23.8 \\
& 20.7 & 34.4 & 29.5 \\
top 10\% & \multicolumn{3}{|c|}{ Marginal Tax Rate } \\
top 5\% & \multicolumn{3}{|c|}{} \\
top 1\% & 20.2 & 33.9 & 29.0 \\
\hline \multirow{2}{*}{ Quantile } & 21.7 & 36.9 & 31.4 \\
1st (bottom 20\%) & 24.9 & 42.9 & 36.5 \\
2nd (20-40\%) & \multicolumn{3}{|c|}{ Share of Tax Payments } \\
3rd (40-60\%) & 2.5 & -3.0 & -4.3 \\
4th (60-80\%) & 5.7 & 3.0 & 4.6 \\
5th (80-100\%) & 13.7 & 11.2 & 12.0 \\
Top & 77.8 & 86.4 & 84.3 \\
10\% & \multicolumn{3}{|c}{} \\
1\% & 62.6 & 71.4 & 69.2 \\
\hline \hline
\end{tabular}

Note: Entries shows average tax rates, marginal tax rates and the distribution of taxes paid (Federal Income taxes) in the benchmark economy, and at higher progressivity around revenue-maximizing levels. 
Table 6: Changes in Labor Supply and Wealth Distribution - Higher Progressivity

\begin{tabular}{|c|c|c|c|}
\hline & $\begin{array}{c}\tau=0.053 \\
\text { (benchmark) }\end{array}$ & $\tau=0.13$ & $\tau=0.10$ \\
\hline & \multicolumn{3}{|c|}{ Labor Supply } \\
\hline Income Quantiles & & & \\
\hline$\overline{\text { 1st (bottom 20\%) }}$ & 100 & 93.9 & 96.7 \\
\hline 2nd $(20-40 \%)$ & 100 & 94.2 & 97.4 \\
\hline 3rd $(40-60 \%)$ & 100 & 94.3 & 96.8 \\
\hline 4 th $(60-80 \%)$ & 100 & 93.4 & 95.3 \\
\hline $5 \operatorname{th}(80-100 \%)$ & 100 & 92.5 & 95.1 \\
\hline Top & & & \\
\hline$\overline{10 \%}$ & 100 & 91.5 & 95.6 \\
\hline $5 \%$ & 100 & 91.8 & 94.6 \\
\hline \multirow[t]{2}{*}{$1 \%$} & 100 & 91.6 & 94.9 \\
\hline & \multicolumn{3}{|c|}{ Wealth Distribution } \\
\hline Wealth Quintiles & & & \\
\hline$\overline{1 \text { st (bottom 20\%) }}$ & 0.1 & 0.7 & 0.5 \\
\hline 2nd $(20-40 \%)$ & 1.7 & 4.3 & 3.2 \\
\hline 3rd $(40-60 \%)$ & 5.9 & 10.2 & 8.5 \\
\hline 4 th $(60-80 \%)$ & 16.5 & 20.9 & 19.3 \\
\hline 5 th $(80-100 \%)$ & 75.7 & 63.9 & 68.5 \\
\hline Top & & & \\
\hline$\overline{10 \%}$ & 57.3 & 45.1 & 49.6 \\
\hline $5 \%$ & 41.4 & 30.5 & 34.5 \\
\hline $1 \%$ & 18.1 & 11.6 & 13.8 \\
\hline
\end{tabular}

Note: Entries in the upper panel show the changes, relative to benchmark economy, in aggregate labor supply associated to higher progressivity. The lower panel shows changes in wealth distribution associated to higher progressivity. 
Table 7: Role of Labor Supply Elasticities

\begin{tabular}{|l|c|c|c|c|c|c|}
\hline & $\tau=0$ & $\tau=0.04$ & $\tau=0.08$ & $\tau=0.10$ & $\tau=0.13$ & $\tau=0.16$ \\
\hline Low Elasticity $(\gamma=0.75)$ & & & & & & \\
Output & & & & & & \\
Labor Supply & 107.9 & 101.9 & 96.2 & 93.4 & 89.4 & 85.5 \\
Revenues & 103.9 & 101.0 & 97.9 & 96.3 & 93.8 & 91.2 \\
Federal Income Tax & & & & & & \\
Corporate Income Tax & 104.1 & 96.5 & 105.3 & 107.8 & 109.7 & 109.7 \\
State and Local Taxes & 107.0 & 101.7 & 97.7 & 95.9 & 93.2 & 90.3 \\
All Taxes & 90.6 & 98.4 & 102.2 & 102.9 & 102.9 & 101.6 \\
& & & & & & \\
\hline Benchmark $\gamma=1)$ & & & & & & \\
Output & & & & & & \\
Labor Supply & 108.7 & 102.1 & 95.8 & 92.8 & 88.4 & 84.2 \\
Revenues & 104.6 & 101.2 & 97.5 & 95.6 & 92.8 & 89.8 \\
Federal Income Tax & 82.1 & 96.7 & 104.9 & 107.0 & 108.4 & 107.7 \\
Corporate Income Tax & 104.7 & 101.2 & 97.3 & 95.3 & 92.1 & 88.9 \\
State and Local Taxes & 107.7 & 101.9 & 96.2 & 93.4 & 89.3 & 85.3 \\
All Taxes & 91.3 & 98.5 & 101.8 & 102.2 & 101.6 & 99.8 \\
\hline High Elasticity $\gamma=1.25)$ & & & & & & \\
Output & & & & & & \\
Labor Supply & 109.2 & 102.2 & 95.6 & 92.4 & 87.7 & 83.1 \\
Revenues & 105.1 & 101.3 & 97.2 & 95.2 & 92.0 & 88.7 \\
Federal Income Tax & 82.7 & 96.9 & 104.5 & 106.4 & 107.2 & 106.1 \\
Corporate Income Tax & 105.3 & 101.4 & 97.1 & 94.8 & 91.4 & 87.8 \\
State and Local Taxes & 108.3 & 102.0 & 95.9 & 93.0 & 88.6 & 84.3 \\
All Taxes & 91.8 & 98.7 & 101.5 & 101.6 & 100.6 & 98.4 \\
\hline
\end{tabular}

Note: Entries show the effects across steady states of changes in the curvature (progressivity) of the tax function for different values of the Frisch elasticity $(\gamma)$. Values of all variables are normalized to 100 in the benchmark economy. The 'All Taxes' row includes Federal income and corporate taxes plus state and local taxes. See text for details. 
Table 8: Role of Revenue Requirements

\begin{tabular}{|l|c|c|c|c|c|c|}
\hline & $\tau=0$ & $\tau=0.04$ & $\tau=0.08$ & $\tau=0.10$ & $\tau=0.13$ & $\tau=0.16$ \\
& & & & & & \\
Benchmark $(\lambda=0.911)$ & & & & & & \\
Output & & & & & & \\
Labor Supply & 108.7 & 102.1 & 95.8 & 92.8 & 88.4 & 84.2 \\
Revenues & 104.6 & 101.2 & 97.5 & 95.6 & 92.8 & 89.8 \\
Federal Income Tax & 82.1 & 96.7 & 104.9 & 107.0 & 108.4 & 107.7 \\
Corporate Income Tax & 104.7 & 101.2 & 97.3 & 95.3 & 92.1 & 88.9 \\
State and Local Taxes & 107.7 & 101.9 & 96.2 & 93.4 & 89.3 & 85.3 \\
All Taxes & 91.3 & 98.5 & 101.8 & 102.2 & 101.6 & 99.8 \\
& & & & & & \\
\hline Higher Revenue ( $\lambda=0.87)$ & & & & & & \\
Output & & & & & & \\
Labor Supply & 106.3 & 99.7 & 93.5 & 90.6 & 86.2 & 81.9 \\
Revenues & 104.6 & 101.1 & 97.4 & 95.5 & 92.5 & 89.5 \\
Federal Income Tax & 118.0 & 129.2 & 134.5 & 135.4 & 134.8 & 132.6 \\
Corporate Income Tax & 104.7 & 100.9 & 96.9 & 94.7 & 91.5 & 88.1 \\
State and Local Taxes & 105.9 & 100.0 & 94.3 & 91.6 & 87.5 & 83.4 \\
All Taxes & 113.4 & 118.6 & 120.0 & 119.5 & 117.8 & 114.9 \\
\hline Higher Revenue ( $\lambda=0.85)$ & & & & & & \\
Output & & & & & & \\
Labor Supply & 105.1 & 98.6 & 92.4 & 89.4 & 85.1 & 80.8 \\
Revenues & 104.5 & 101.0 & 97.3 & 95.4 & 92.4 & 89.3 \\
Federal Income Tax & 134.9 & 144.6 & 148.5 & 148.7 & 147.3 & 144.1 \\
Corporate Income Tax & 104.6 & 100.7 & 96.6 & 94.4 & 91.1 & 87.6 \\
State and Local Taxes & 104.9 & 99.1 & 93.4 & 90.6 & 86.5 & 82.5 \\
All Taxes & 123.8 & 128.0 & 128.5 & 127.6 & 125.3 & 121.9 \\
\hline
\end{tabular}

Note: Entries show the effects across steady states of changes in the curvature (progressivity) of the tax function for different values of 'level' parameter $(\lambda)$ in the tax function. Values of all variables are normalized to 100 in the benchmark economy. The 'All Taxes' row includes Federal income and corporate taxes plus state and local taxes. See text for details. 
Figure 1a: An Increase in Labor Supply Elasticity $(\gamma)$

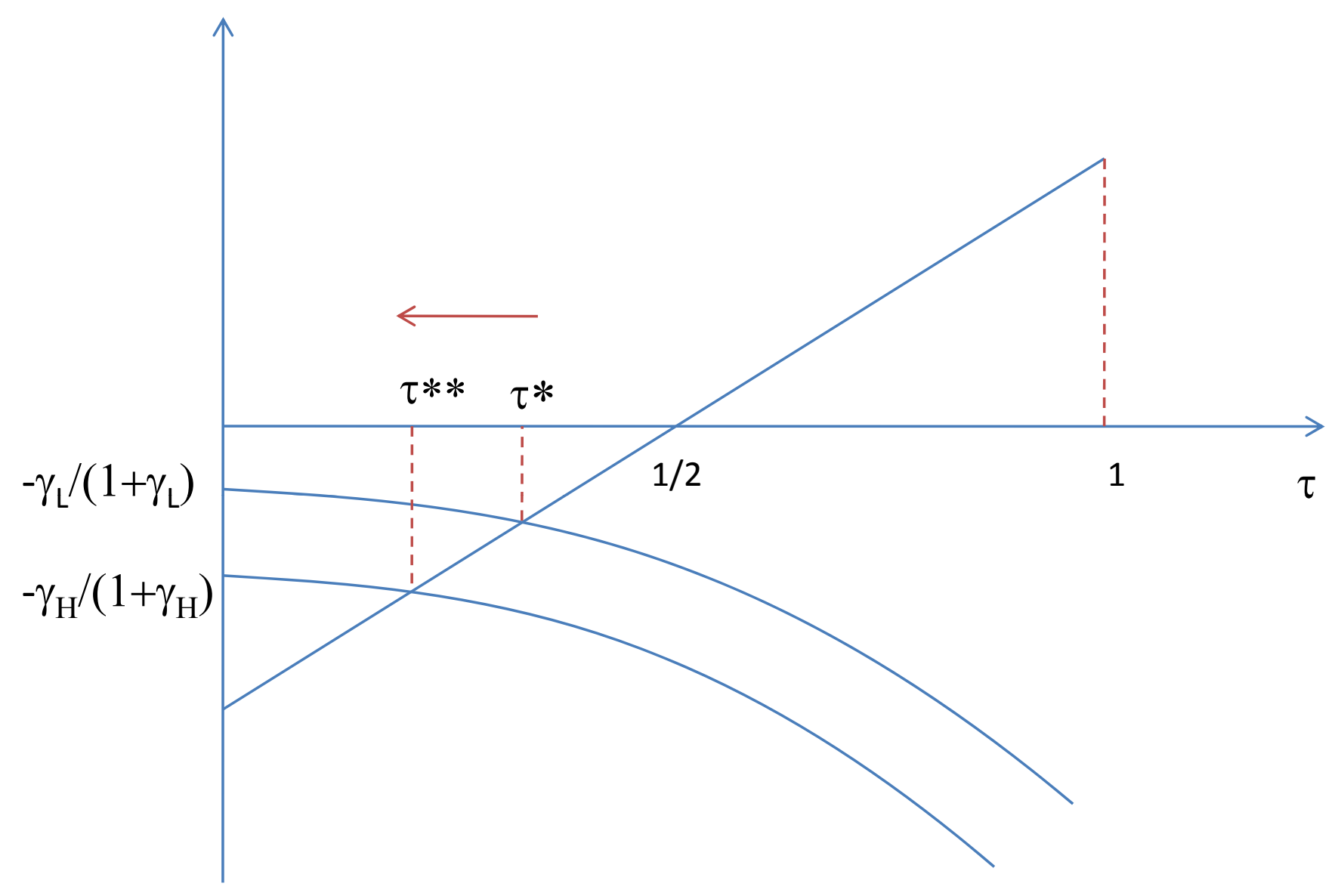


Figure 1b: An Increase in Wage Dispersion $\left(\sigma^{2}\right)$

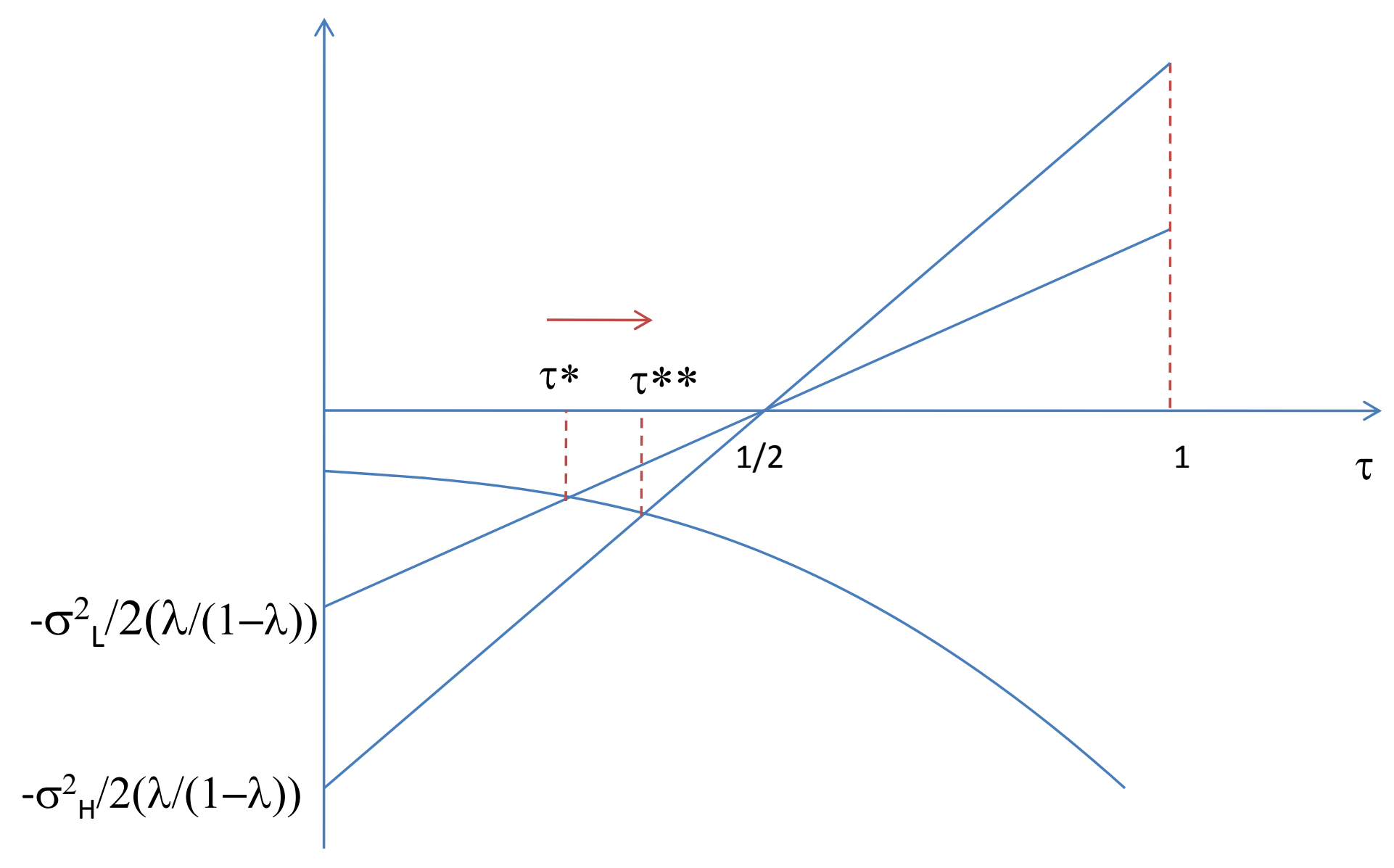


Figure 1c: An Increase in Average Taxes ( $\lambda$ )

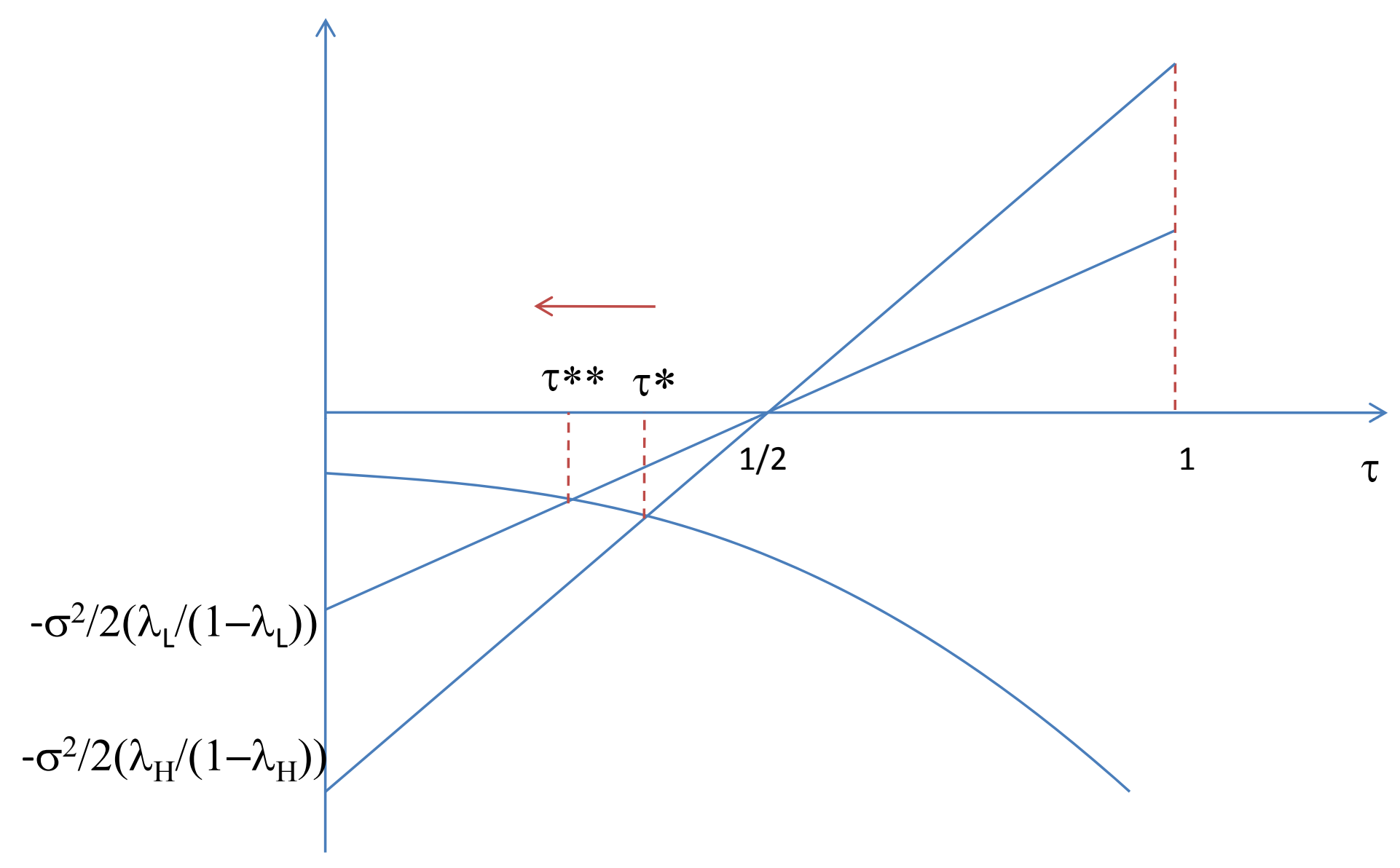




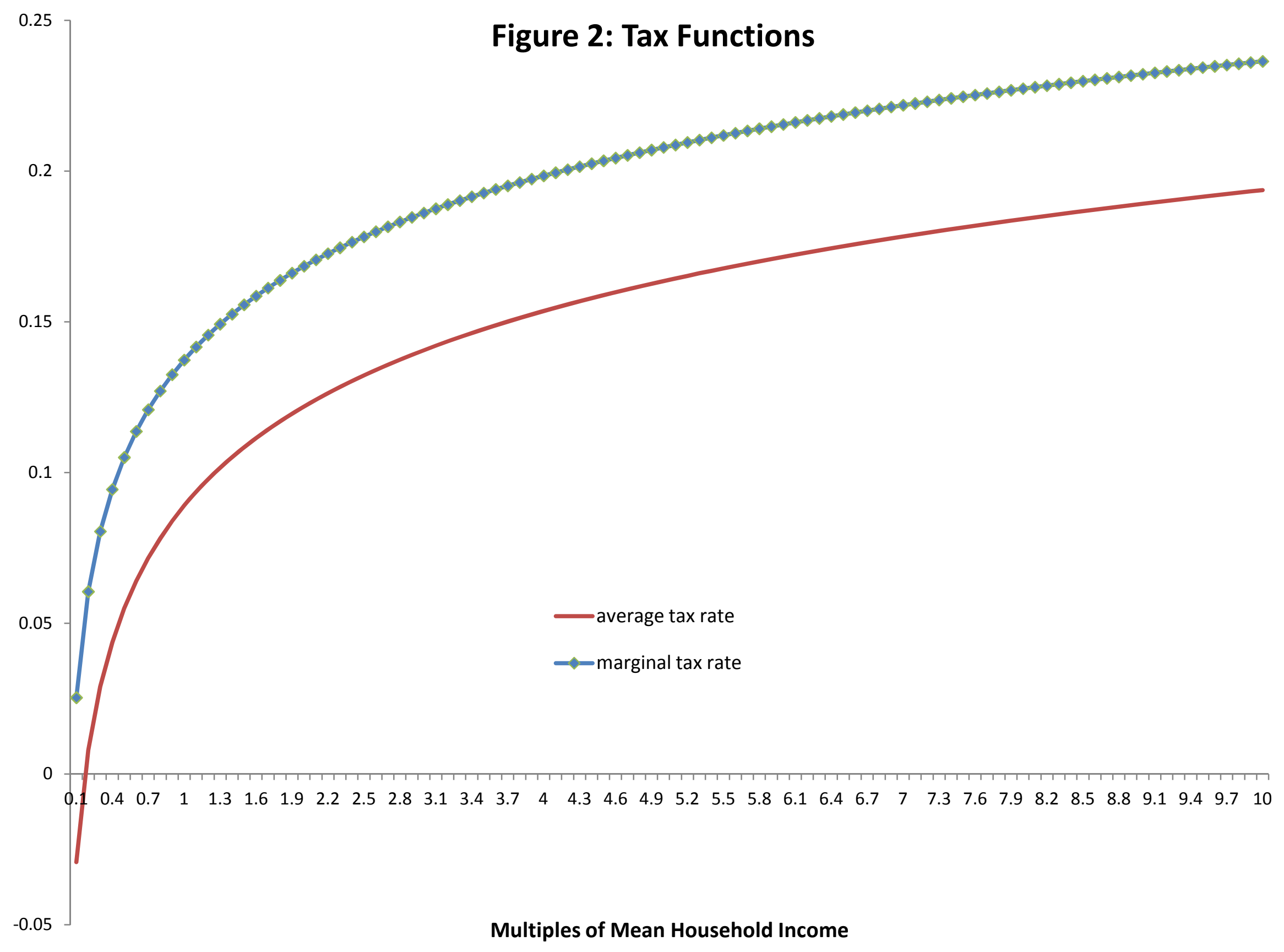




\section{Figure 3-a: Labor Supply, Capital and Output}

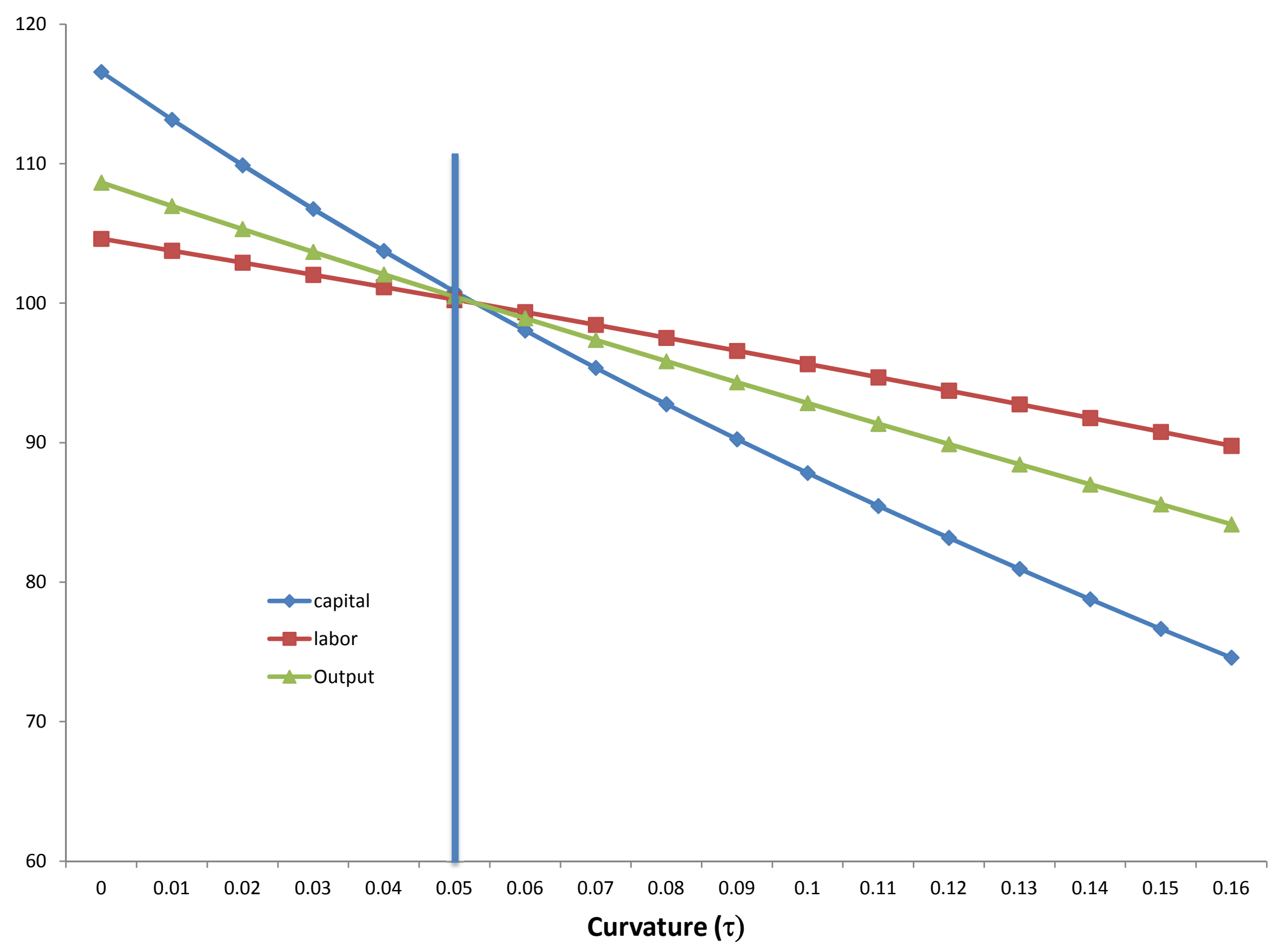


Figure 3-b: Federal Income Tax and Total Tax Revenue

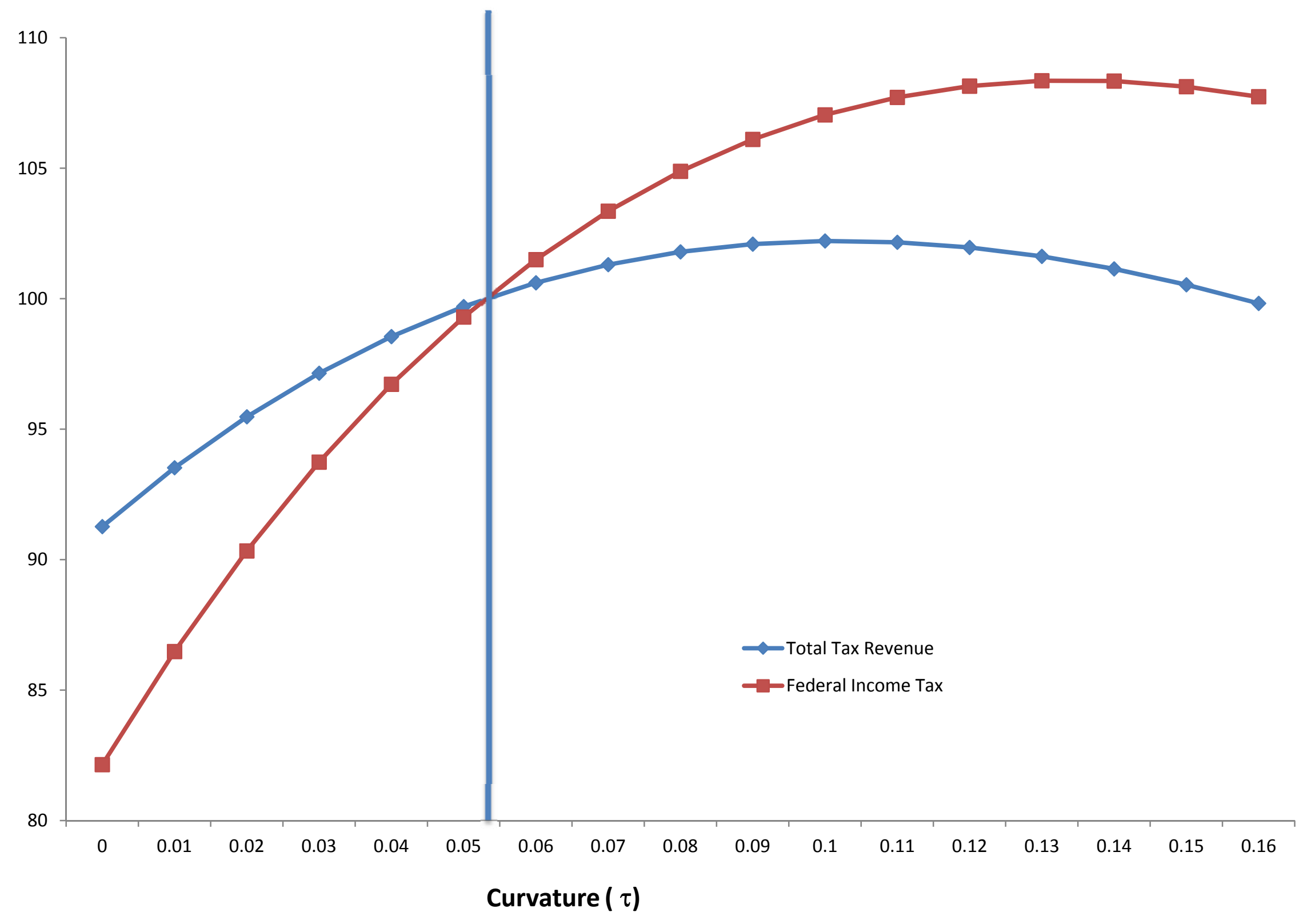




\section{Figure 4-a: Effect of Labor Supply Elasticity}

Federal Income Tax Revenue

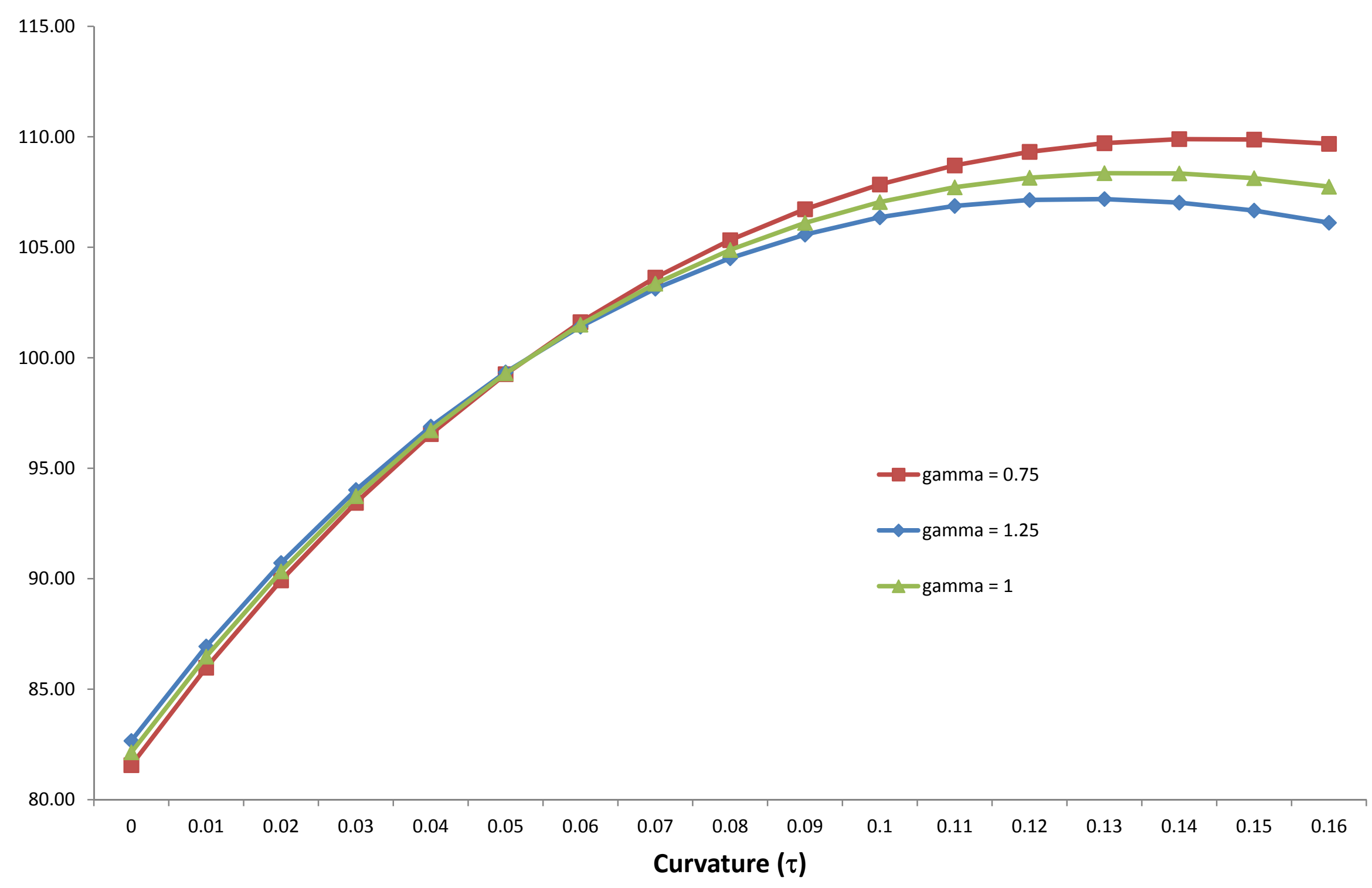


Figure 4-b: Effect of Revenue Requirements Federal Income Tax

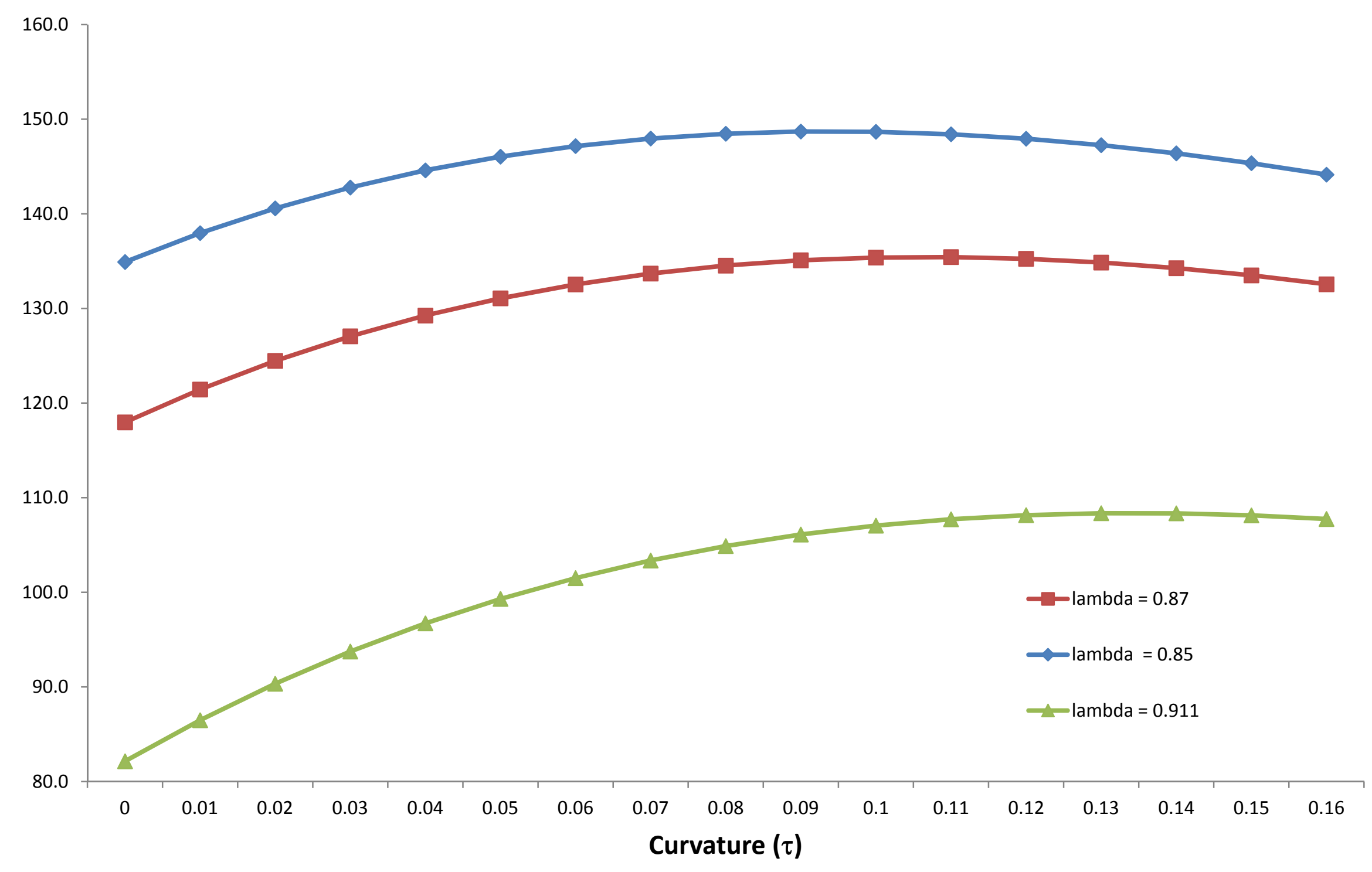

